 \\ Journal of \\ Human, Earth, and Future
}

ISSN: 2785-2997

Vol. 2, No. 3, September, 2021

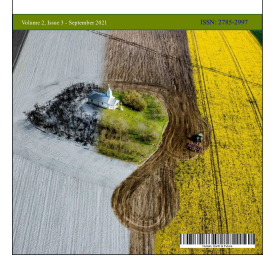

\section{Evaluation of Geology and Hydrogeology of the Water Leakage in Hammam-Grouz Dam, Algeria}

\author{
A. Toumi ${ }^{1 *}$, B. Remini ${ }^{2}$ \\ ${ }^{1}$ Laboratory of Civil Engineering and Hydraulics ( $\left.L G C H\right)$, University of Guelma, Algeria \\ ${ }^{2}$ Department of Water Sciences, Faculty of Blida University, Blida 9000, Algeria
}

Received 27 June 2021; Revised 09 August 2021; Accepted 16 August 2021; Published 01 September 2021

\begin{abstract}
Water has been known since antiquity as the catalyst and survival of mankind. Therefore, hydraulic structures have been constructed to resolve various hydraulic problems which are exposed, such as pollution, eutrophication, accelerated siltation, intense evaporation, and water leakage. In Algeria, the problem of water leaks has appeared in many dams, among them the Hammam Grouz dam in the north-east of the country. Indeed, hydro-technical work is considered the most threatened in the country by this thorny problem. During the period between 1984-1987, there was a lack of suitable sites for dam construction in this area, which led the services concerned to build this infrastructure in a cluse composed of limestone (Cenomanian) moderately karstic, which is characterized by dissolutions concentrated along the joints. This site was consolidated and sealed during the construction of the dyke dam that allows its exploitation before a real test. However, it should be noted that the water level rose above the normal reservoir level for the first time on January 26, 2003, showing that this site can no longer withstand the strong pressure forces caused by the coastline water. In fact, significant water leaks have appeared in the lower gallery and at the downstream foot of the right bank. The following variation of water leaks over time can be observed to have a convergence of stability of the level of the water level in the bowl to levels not exceeding $718 \mathrm{~m}$, which is the equivalent of less than $1 / 3$ of the original storage capacity of the dam. The appearance of significant water leaks at the Hammam Grouz dam as soon as the spill was first discharged indicated that the sealing works carried out during the construction of the dyke had either lost their effectiveness or weren't perfect. The settlement works were carried out today at the level of the basin and the banks of this hydraulic infrastructure. Despite having minimized the flow of the resurgences that appeared downstream of the dike, they did not solve the problem definitively. This may result in the appearance of a place where water is leaking. Indeed, during the hydrological year 2007/2008, the appearance of a vortex in November 2007 within the lake rendered the dam of Hammam Grouz useless because it was empty during the first three months of the year 2008, in addition to the water loss that threatened them. This phenomenon floods the lower gallery of the dyke with each rise of the level of water beyond a limit threshold. Hence, it is impossible to perform some monitoring related to stability control. The harmful effects of the problem of water leakage, the stability of the dike and the quantity of water stored, especially with water scarcity in this semi-arid region, require treatment of this phenomenon. The most adapted techniques are those that use sealing materials. Having the same characteristics as the places to be waterproofed and which adapt sufficiently to their geological formations, the allocation of sealing works to a highly qualified co-contractor is of great importance in order to provide satisfactory sealing results to make them watertight in order to operate them properly.
\end{abstract}

Keywords: Dams; Algeria; Leaks; Water; Hammam Grouz; Rives; Bowl; Foundation.

* Corresponding author: toumiouaheb@yahoo.fr

doi) http://dx.doi.org/10. 28991/HEF-2021-02-03-08

$>$ This is an open access article under the CC-BY license (https://creativecommons.org/licenses/by/4.0/).

(C) Authors retain all copyrights. 


\section{Introduction}

Water leaks through the banks and the foundation of dams is one of the thorny problems that a dam encounters. In Algeria, the dams of Foum El Gherza [1], Ouizert [2], K'sob, Djorf-Etorba [3], and Beni Haroun [4] and others suffer from colossal water losses over time. Hammam Grouz dam is the most exposed to this problem [5]. The sealing works carried out since the appearance of this problem at the level of the basin and the banks of the dam have not solved the problem definitively. Moreover, there is a reappearance of the problem every time the water level in the bowl approaches the normal level of restraint. Despite the construction of the Beni-Haroun dam downstream of HammamGrouz [4], it has not been able to meet the demand for water throughout the region. The Hammam Grouz dam, in addition to the water reserves it stores, preserves the downstream areas against repeated floods of the Rhumel River and protects this large dam against siltation, which requires special attention, especially to problems threatening its stability such as water leaks. In this paper, we focus on the problem of water leaks at Hammam Grouz dam based on measurements taken from its first impoundment, the data available on the subjects of geology and hydrogeology, and techniques to disclose it in a clear and refined way to find appropriate remedies which might be needed.

\subsection{Presentation of the Study Area}

Hammam Grouz dam is located in the north east of Algeria about $400 \mathrm{~km}$ east of the capital Algiers (Figure 1). The dam site is located in the Wilaya of Mila, $1.5 \mathrm{~km}$ south of the city of Oued Athmenia and $45 \mathrm{~km}$ southwest of the city of Constantine (See Figure 1). It is upstream of a gorge incised by the Oued Rhumel in the Cretaceous limestones (Cenomanian) which form the Djebel Grouz [6].
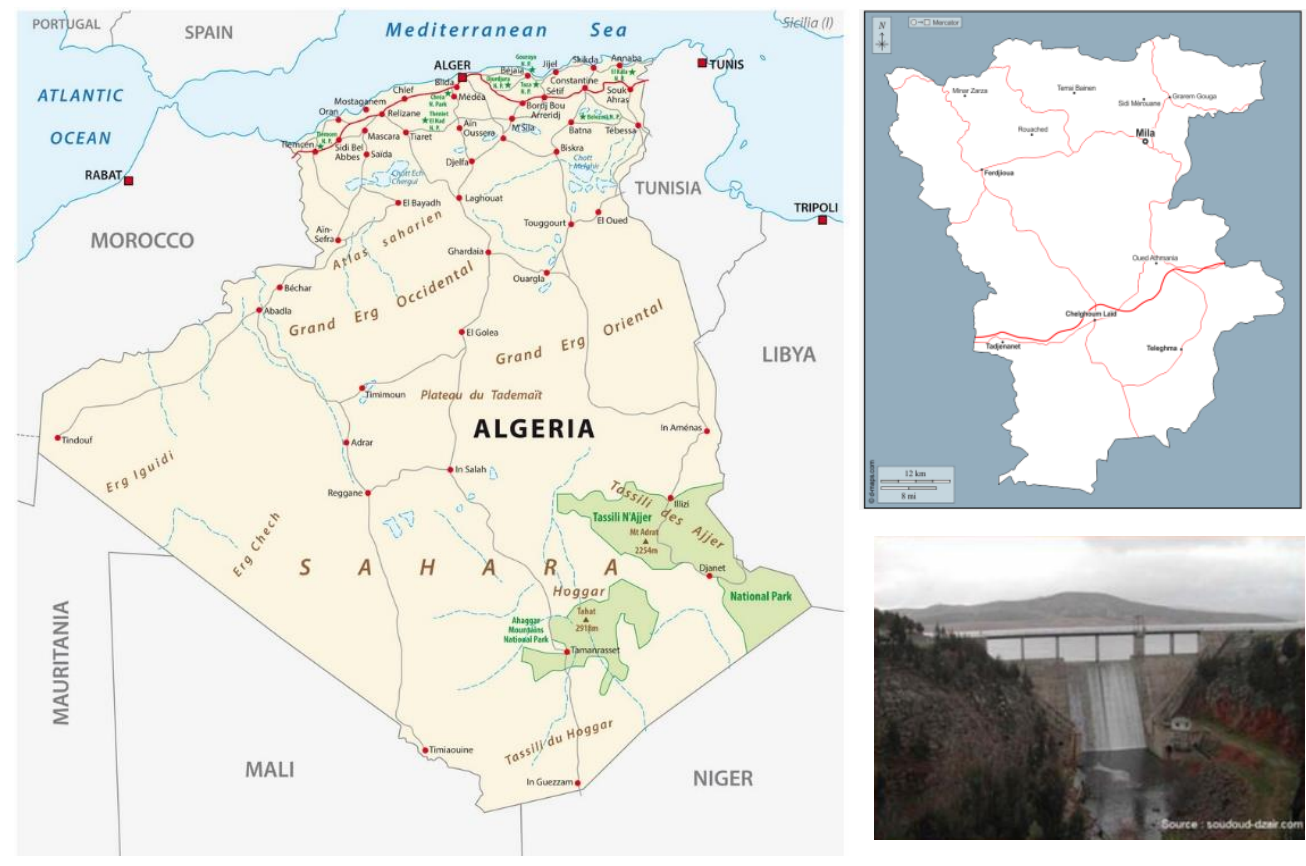

Figure 1. Geographic situation of Hammam Grouz dam, Algeria

The dam has a capacity of $45 \mathrm{Hm}^{3}$ on the normal side of the reservoir, drains around $15 \%$ of the surface of the basin are controlled by the large dam, at the national level, of Beni Haroun. The latter being carried out on the Kebir river, downstream from the confluence of the rivers Rhumel and Endja (see Figure 2) [7].

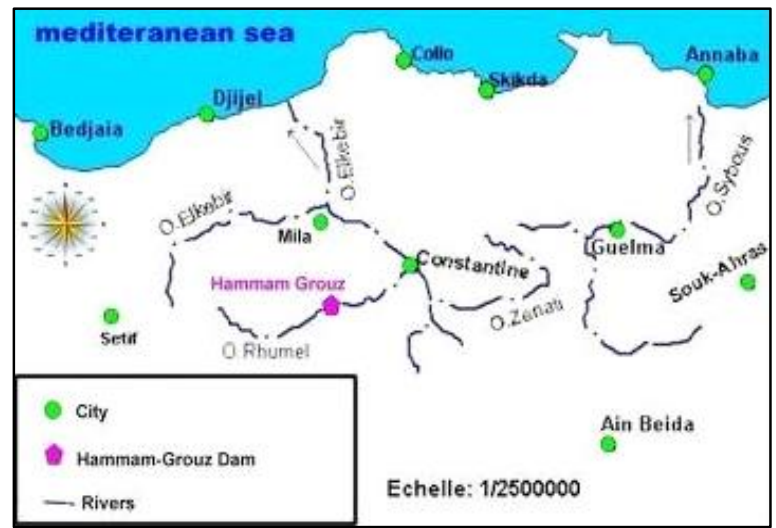

Figure 2. Geographic and hydrographic situation of Hammam Grouz dam in the northeast region of Algeria 
Hammam-Grouz dam's height is of $49.5 \mathrm{~m}$. In concrete-weight, it shows an upstream face inclined from the foundation to the level of the top of the clay carpet at $705 \mathrm{~m}$ side. Above this carpet, the face of the dam is vertical. However, the weir of the dam takes the form of that of Creager-Ofitserov and fulfills the stability conditions (See Figure 3) [8].The highest water mark is $736.50 \mathrm{~m}$ while the normal flood level is $727 \mathrm{~m}$. The length of the ridge reaches $217 \mathrm{~m}$ (see Figure 3) [9].

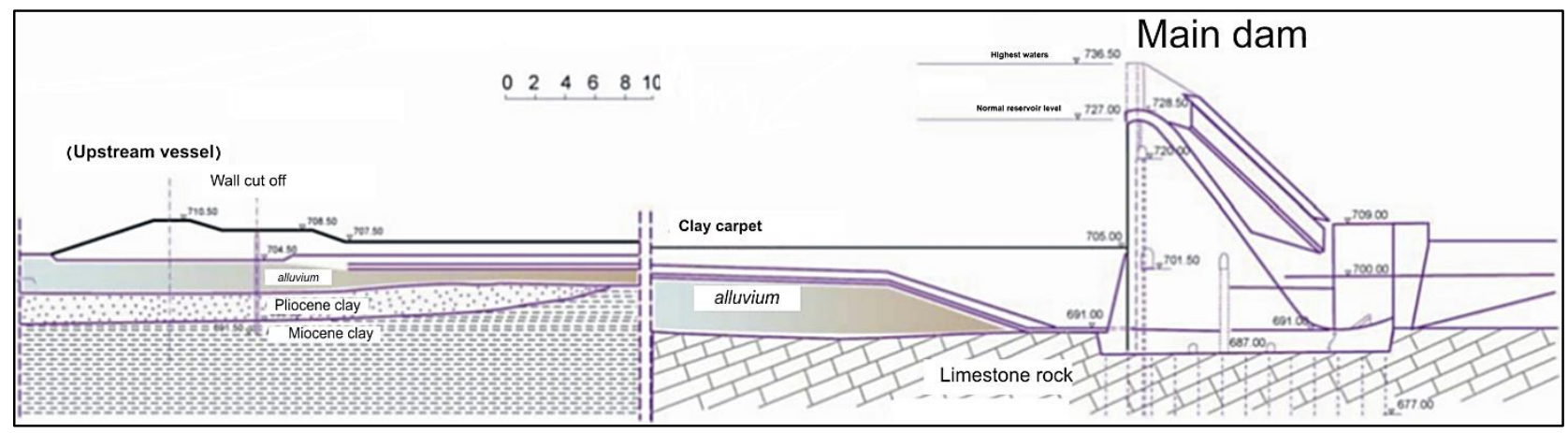

Figure 3. Cross section, along the valley, of Hammam-Grouz dam, Algeria

At the beginning of its commissioning, it is intended to supply drinking water to the cities of Constantine and Oued Athmenia and to provide flood protection for all the property and the population along the river. Rhumel, especially, the town of Oued-El-Athmenia located downstream near the dike. Figure 4 shows the position of the town of Oued Athmenia downstream of the dam.

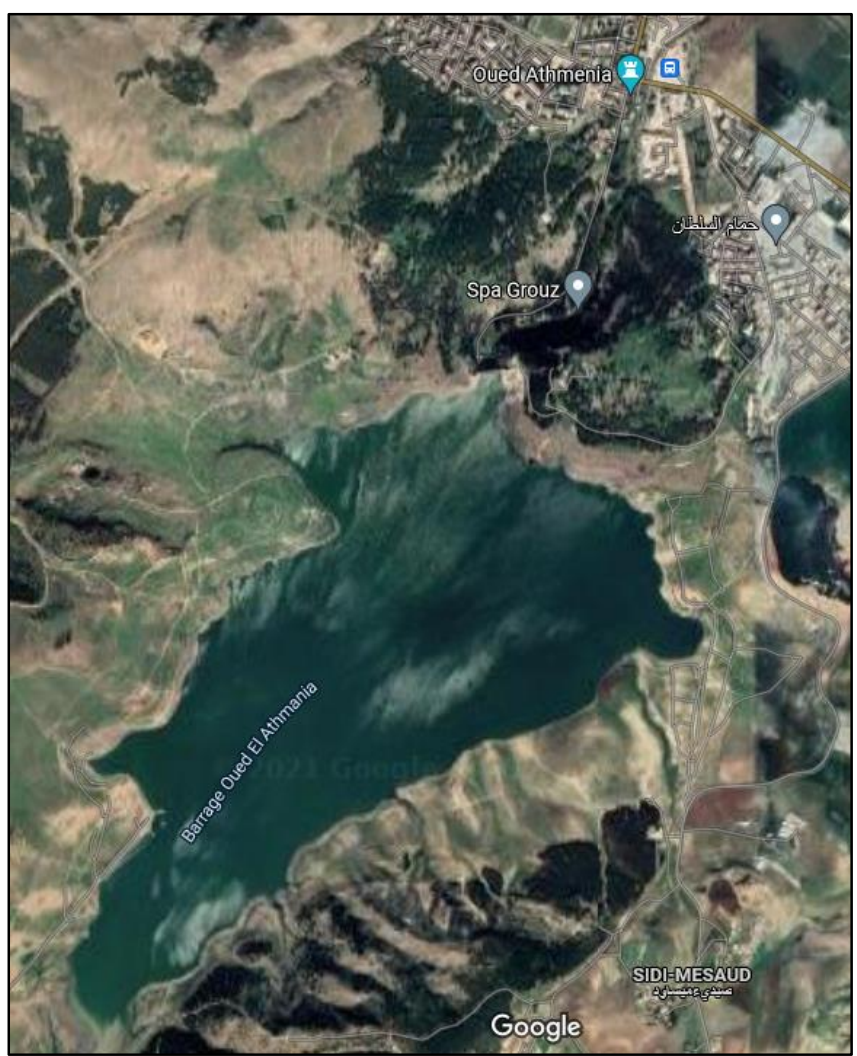

Figure 4. Satellite photo of Hammam Grouz dam

The dam was built in limestone cluse of Hammam Grouz, upstream of the town of Oued Athmenia [10]. The first watering was in February 1987 and the work has been in operation since September 1989 [9]. From that date until the years 2001-2002, the Hammam-Grouz dam operating under normal working conditions, without any major problems of functioning with rainy episodes and other dry iterative governing the dam supply. The spillway of this hydraulic infrastructure experienced, for the first time, a spill in January 2003, following an exceptional rainfall that affected the Center and East of the country (see Figure 5) [9]. The hydrological contributions of this wet year 2002/2003, at the level of the dyke of the Hammam-Grouz dam, were estimated by the National Water Resources Agency (N.W.R.A) at 65 million $\mathrm{m}^{3}[11]$. 


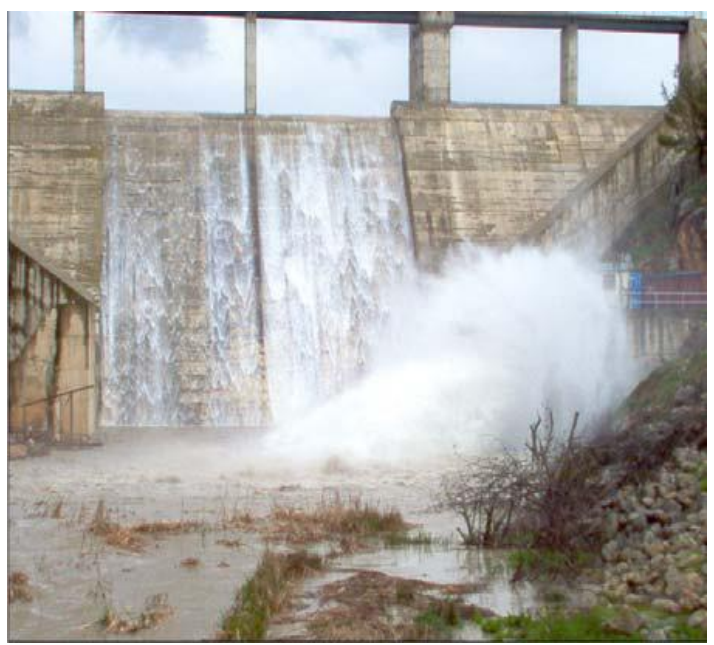

Figure 5. First water discharge at Hammam Grouz dam in January (2003)

This spill, which lasted from January 28, 2003 until April 27, 2003, brought the level of water in the lake to a level higher than the normal level of containment $(727.00 \mathrm{~m})$ and just at a level of $727,08 \mathrm{~m}$ which puts the supports and the basin of the dam under exceptional pressure [12]. This pressure led to the appearance of twelve (12) resurgences downstream and more precisely on the right bank of Rhumel river (see Figure 6), with a flood of the lower gallery (see Figure 7). Figure 8 represents an approximate diagram of the places of the resurgences generated downstream of the dike.

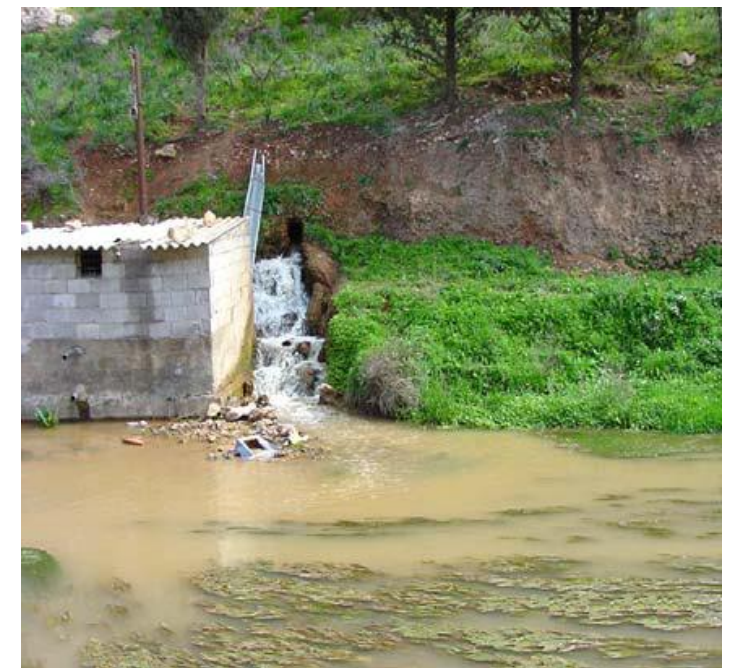

Figure 6. Appearance of resurgences downstream of the right bank of Hammam Grouz dam

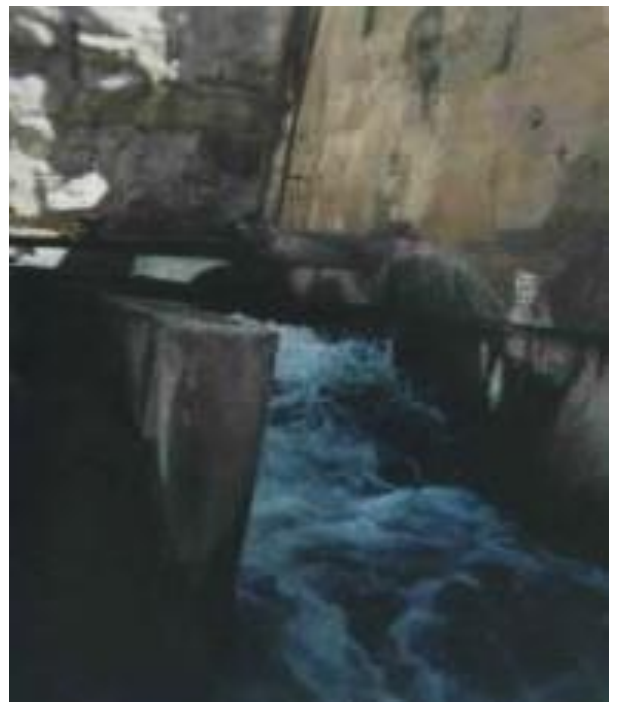

Figure 7. Flooding of the lower gallery 


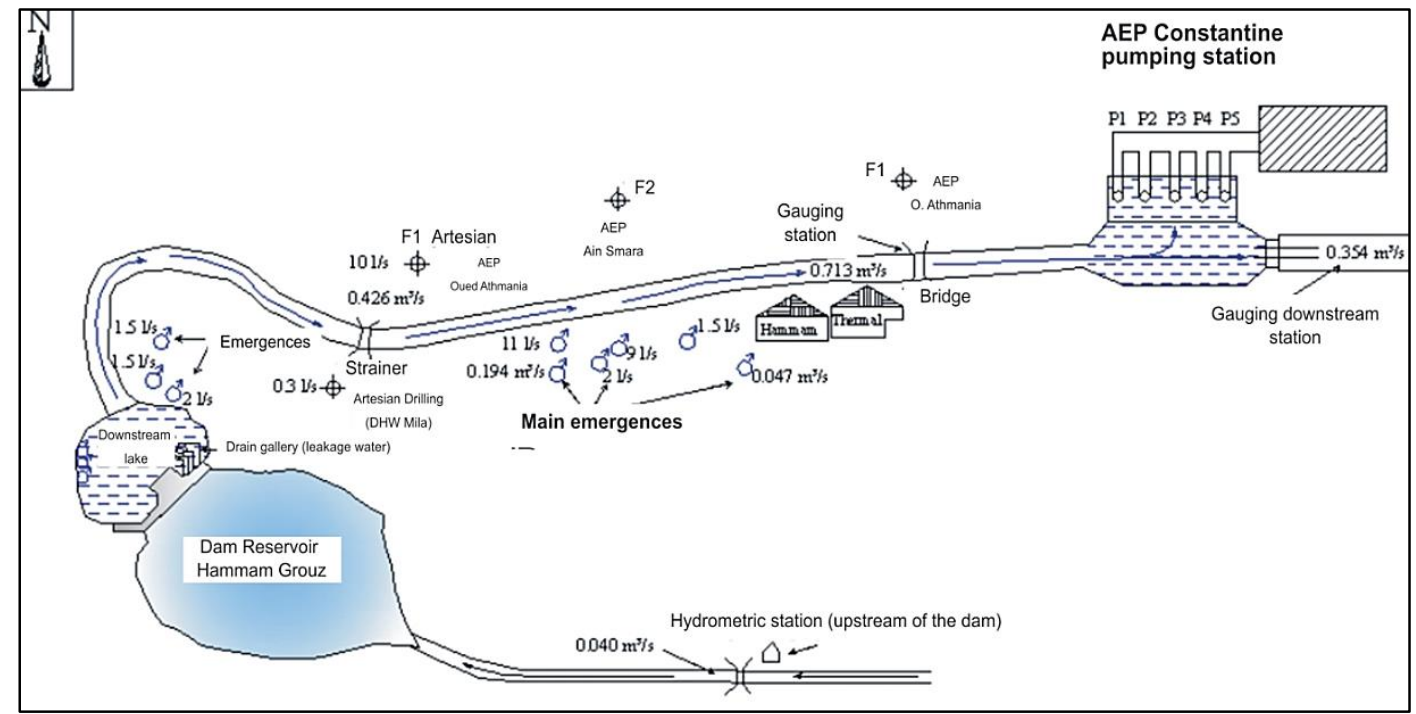

Figure 8. Rough diagram of the resurgences appeared downstream from Hammam Grouz dam

Despite its importance to the region, this hydrotechnical infrastructure encounters difficulties in storing water in its basin. These difficulties may be caused by serious problem of water leaks through its foundation and its supports due to geological imperfections. Indeed, giant resurgences with different flow rates have been observed downstream of the dike. These resurgences (see Figures 6 and 9) disrupted the exploitation of the boreholes located downstream of the dike. In fact, the sheet of water downstream of the dyke was put under pressure. Figure 10 illustrates the state of a borehole located about $80 \mathrm{~m}$ downstream of the dyke. They can jeopardize the safety of the dike by minimizing the operating role of some of its annexes, for example when the lower gallery is immersed a large number of instruments will be malfunctioning and consequently several auscultation measures may be discontinued.

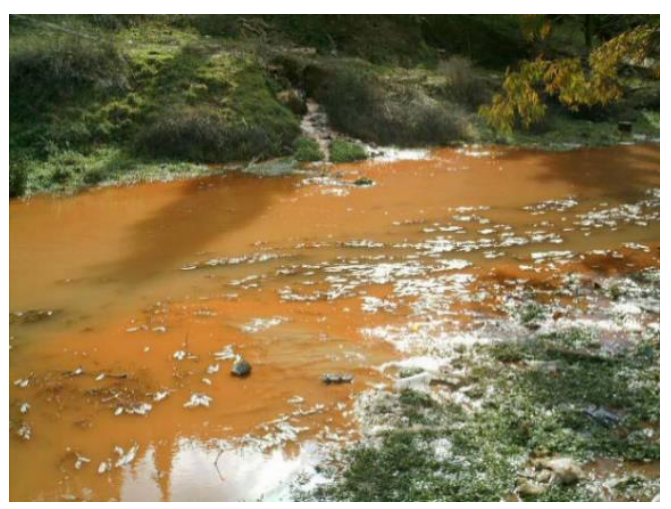

Figure 9. Reddish leakage water downstream of Hammam Grouz dam photo taken at the right bank



Figure 10. A pressurized borehole located downstream from the dike of Hammam Grouz dam 
Harmful effects generated by the phenomenon of water leakage, it will be advised to circumscribe its causes and to study in detail this phenomenon taking into account all the parameters that will help, first of all to its detection and what are the techniques and methods which can be used to identify the defective area and suggest actions for their recovery.

The lack of a site for the construction of a favorable dam to the storage of water led the services of hydraulics to realize the dam of Hammam-Grouz on the oldest limestones (Cenomanian) which is much fractured where the limestone facies is monotonous [6]. These fractures favor feeding and water infiltration and give rise to a very developed superficial karst with numerous karst forms (sinkholes, siphon, cavities, etc.). Figure 3 shows a longitudinal section of the dam site, where its basin contains Pliocene and Miocene clays with a generally thin cover of quaternary deposits. Based on the geological study established by the expert Bielefeld during the preliminary project, studies of limestone karstification at the Hammam Grouz dam site made it possible to classify the limestones of the site among the medium karst limestones and the dissolving effects which are considered as concentrated effects along the joints. During the dam construction phases, consolidation work was adopted to ensure water tightness in order to minimize the probable leakage potential from the basin through foundation and supports of the medium karst limestones. However, this solution has been lost, during time, and its effectiveness has been moderately executed. Indeed. Dissolution crack (siphon) in right bank limestones and other karstic features were excavated, cleaned and then compacted prior to placement of the covering carpet. But the question to be raised in this vein is: are these works optimal for limestone dissolution cracks that change in contact with water over time?

The two so-called sinkholes have undergone a particular treatment, one being filled with sand and then with mass concrete, the other one was filled with several filtering layers. But these questions also arise: could this treatment not be modified? Would this lead to the reappearance of the old sinkholes? Concequently, this may allow major leaks to the underlying limestone and jeopardize the safety and operation of the work and its annexes. Figure 11 shows the sealing work done during the construction of the Hammam-Grouz dam. The impermeable carpet is installed upstream of the Hammam Grouz dam, a clay portion covering the limestone outcrops and permeable alluvium, the other shotcrete and concrete-slabs surrounding the flanks. It is designed to minimize water loss from the bowl by capping the water circulation corridors in the underlying foundations. The waterproofing actions carried out during the construction of the dike to stop the escape of water from the lake are not perfect. Indeed, during the first pressurization of the geological layers, giant water leaks were observed downstream of the dike and the waters of some resurgences have a reddish color (see Figure 9). It gives the impression that there is a dissolution of the red clay used either on the clay carpet or on the filling of sinkholes and siphons.



1) Main dam; 2) Upstream belt, sprayed concrete slab; 3) Upstream belt, concrete slab; 4) Clay carpet; 5) Upstream cofferdam; 6) Draining cord; 7) Splash wall; 8) Rockfill; 9) Neck dike; 10) Drainage gallery

Figure 11. Diagram of the waterproofing work carried out during the construction of the dike of Hammam Grouz dam 


\section{Materials and Methods}

The following materials were used in the present research.

\section{- A Probe Beep}

This device is used to measure the water level in the piezometers. It has two electrodes connected to a multidecameter when these electrodes touch the water level in the piezometer, the electrical circuit and the device emits a beep. The results are read from the multidecameter that states the value of the depth at different sets on the roof of the water column.

\section{- A gauge}

It is installed in the dike of the dam; it is used to read the symbol of the lake.

\section{- Data Recorded}

All the data which have been collected were related to the following aspects: rainfall, flow leakage, evaporation, the lake ratings, piezometric ratings etc.

\section{- Methods}

The determination of the water circulation corridors and the direction of underground flow showing more than necessary or even obligatory to understand the mechanism of the phenomenon of leakage of water due to infiltration. To achieve these objectives, the exploitation of all the information collected, at the level of the dam or even at the scale of the watershed, will be very useful.

Understanding the phenomenon of water leakage at the Hammam Grouz dam callus to start research by highlighting all the events and the works that the dam has undergone since the beginning of the construction works of the dike to the present day. The main concept behind is to search for relationships between precipitation, hydrometric flow and leak flow, has led to a study of the surface flows, the hydraulic balance and leak flow rates at the dam scale.

The procedure of this work has three main sections: First, we will try to put an interpretation of the variation of the level of the body of water over time. Then, we focus on finding a relationship between the flow rates of water leaks and the water levels in the bowl. Followed by making a piezometric study in order to know if there is a hydraulic connectivity or not between the water of the installed piezometers and the water of the basin and to try to draw, as far as possible, the expressions of relationships linking these parameters. Finally, drawing the curve representing the average speed of infiltration according to the level of the water level in the dam basin will also be one of our main objectives.

The general objective of this study is to find a reliable and meticulous approach that will allow us to appreciate the degree, causes, consequences and the variation of the water leaks at the Hammam Grouz dam in order to develop ideas allowing us to find solutions to this thorny problem in order to minimize it as much as possible.

\section{Results and Discussion}

Since the impoundment of the dam in 1987 [4], the spillway has never operated because of the small amount of water received at the lake. During the period from January 28, 2003 to April 27, 2003, and because of heavy rainfall in its watershed, the lake was at a higher level than the main spillway (A.G.L 727.00).This water level of the lake created an almost constant and permanent hydrostatic pressure force on the dam's supports during this period. This caused considerable water losses in 20/04/2003 through especially the right bank. The geology of the site, which is composed mainly of Cenomanian limestones moderately karstic and with dissolutions along the joints [1], and the absence of perfect consolidation works, especially at the level of the right bank, are the main causes of these water leaks [13-15]. Underground flow created by hydrostatic pressure has contributed to the entrainment of sealing materials by expanding the underground corridors of water circulation by Renard phenomenon and dissolution effects.

\section{Detection, Understanding and Works against the Phenomenon of Water Leakage at Hammam-Grouz dam}

The detection of leaks in a dam is done through the use of techniques and fairly extensive means, the reason why the National Agency of the dams and transfers (N.A.D.T) charged the Center of Nuclear Research of Algiers (A.N.R.C) to carry out this task at the Hammam-Grouz dam, since the understanding and the detection of this thorny phenomenon make it possible to look for the real causes, to propose the most adequate solutions and to start the necessary works where it would be necessary by the materials the most adapted.

To determine the origin of the water flowing downstream of the dike is what it belongs to the lake water or the groundwater of the region on the one hand and the determination of the origin and levels of water infiltration in the lake led the Algiers nuclear research Center (A.N.R.C) initiated some actions divided into two phases. 


\section{First Stage}

\section{- Tracing with Rhodamine}

The first findings, on the location of the resurgence sites, claim that most of the spurts downstream of the dike have appeared at the bottom foot of the cliff on the right bank, which gives an idea that this shore is the more vulnerable to leakage of water from the dam lake. However, approval confirmation that the waters of these resurgences have no other origin must be justified by the application of a technique based on tracers. These findings led the CRNA researchers to perform a preliminary detection by tracing with Rhodamine-WT at the lake, on the right flank. For this purpose, a volume of four liters of Rhodamine was injected on the right side of the lake, as shown in figure 12.

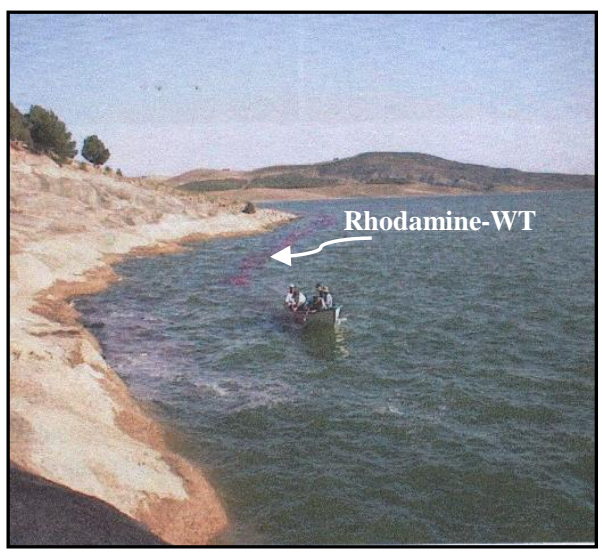

Figure 12. Tracing with Rhodamine - WT at the lake of Hammam Grouz dam

Two automatic samplers were placed, one at the resurgence 01 downstream, near the drainage gallery and the other a little further downstream, next to a platform (resurgence 02) with a step of time of 45 minutes (Figure 13).

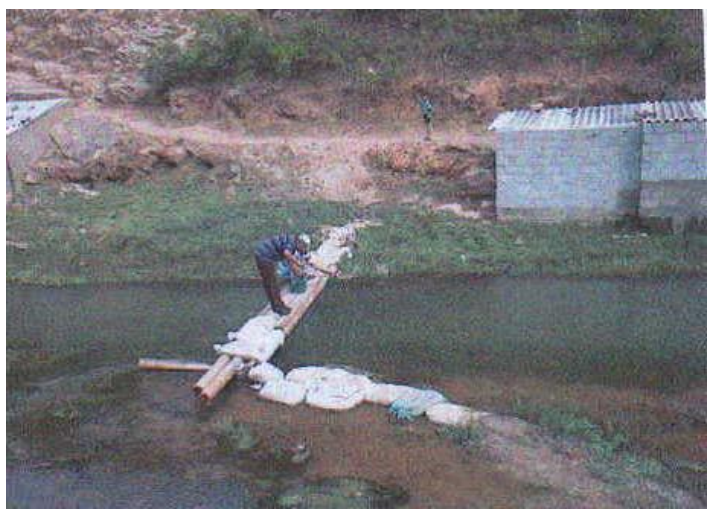

Figure 13. Automatic sampler at resurgence number two located downstream of Hammam Grouz dam

The Rhodamine signal downstream of the dam (Figure 14) confirms the hypothesis that the leaks at the level of the resurgences come from the reservoir and not from the aquifers of the region.

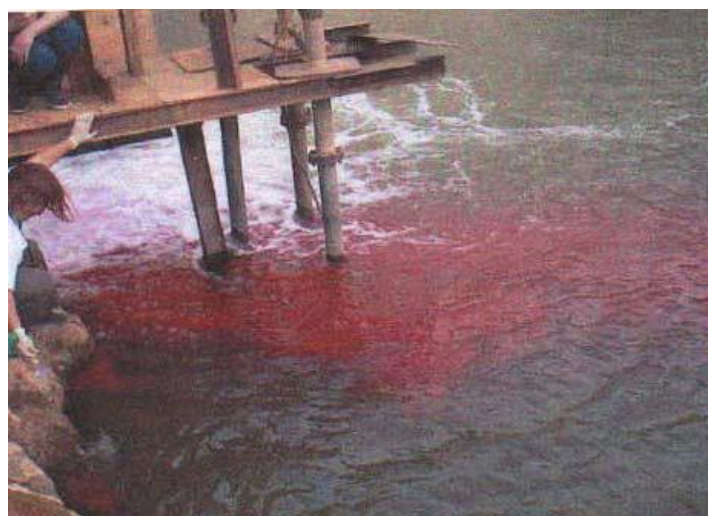

Figure 14. Rhodamine response downstream from the dike of Hammam Grouz dam 


\section{- Temperature and Conductivity Profiles}

After being sure that the waters resurging downstream belonged to the waters of the basin. The determination of the infiltration levels and the knowledge of the origin of the water from all sources downstream are of a great importance. For this purpose, N.A.D.T. engineers and A.N.R.C. researchers carried out measurements of the temperature and conductivity of all the resurgences located downstream or even sometimes upstream of the reservoir [16, 17].

On June 29, 2003, conductivity and temperature measurements were carried out at all the resurgences located downstream of the dike and the results show conductivity values between 705 and $751 \mu \mathrm{s} / \mathrm{cm}$ and temperature that oscillate between 19 at $20.3{ }^{\circ} \mathrm{C}$ (Table 1 and Figure 15).

Table 1. Conductivity and temperature results at resurgences located downstream of the dike

\begin{tabular}{cccccc}
\hline Measuring Point & Cond $(\boldsymbol{\mu s} / \mathbf{c m})$ & $\mathbf{T}\left({ }^{\mathbf{C}}\right)$ & Measuring Point & Cond $(\boldsymbol{\mu s} / \mathbf{c m})$ & $\mathbf{T}\left({ }^{\circ} \mathbf{C}\right)$ \\
\hline S1 & 732 & 19.4 & S7 & 705 & 20.3 \\
S2 & 732 & 19.4 & S8 & 708 & 20.1 \\
S3 & 714 & 19 & S9 & 711 & 19.9 \\
S4 & 751 & 19.9 & S10 & 700 & 20.3 \\
S5 & 705 & 20.3 & S11 & 708 & 20.2 \\
S6 & 705 & 20.3 & S12 & 707 & 20.6 \\
\hline
\end{tabular}

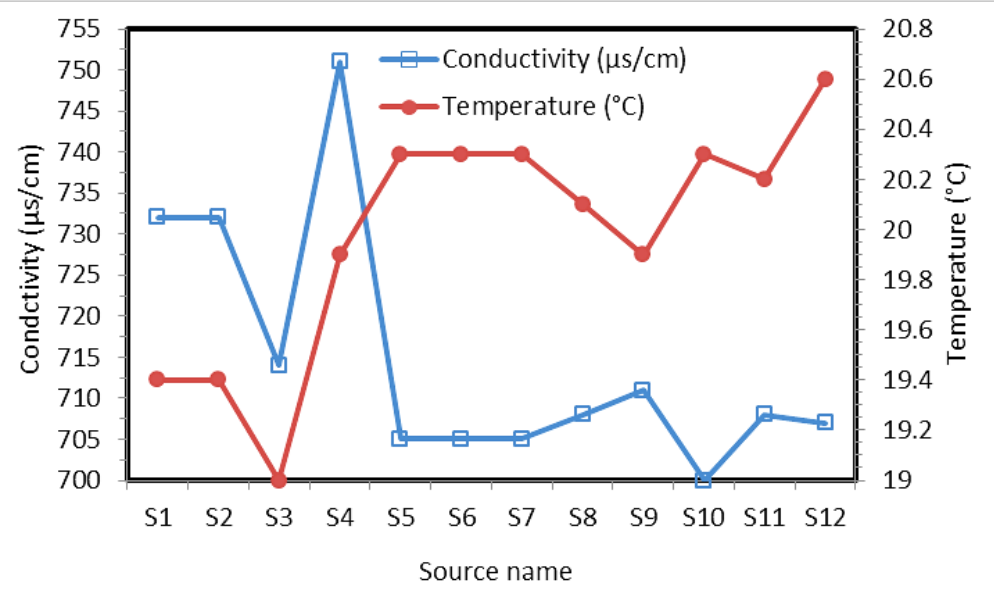

Figure 15. Fluctuation in conductivity and temperature at various resurgences located downstream from the dike of Hammam Grouz dam

These values can be compared with those of the boreholes upstream and downstream of the dam, in order to know if the water of the resurgences comes from the same origin, that is to say of origin underground or it is losses of the water from the dam lake.

On June 30, 2003, sampling of two holes, one upstream (borehole named Bouffoula) of the reservoir and the other known as Kasseh drilling downstream on the right bank, were carried out. The results of the two parameters: temperature and conductivity are shown in Table 2.

Table 2. Conductivity and temperature results at selected boreholes

\begin{tabular}{ccc}
\hline Borehole position & Cond $(\boldsymbol{\mu s} / \mathbf{c m})$ & T $\left({ }^{\circ} \mathbf{C}\right)$ \\
\hline Downstream of the dike & 2500 & 37.5 \\
Upstream of the dike & 1695 & 20.7 \\
\hline
\end{tabular}

On July 01, 2003, the group began a second step for the realization of four (04) profiles, in depth, of temperature and conductivity within the lake of the dam to detect the probable slice of infiltration. The choice of the position of these profiles is guided by the findings, the previous results and the places likely to be infiltration zones, which leads the group chose the following locations:

- First profile: in front of the structure (Vortex 01) at $10 \mathrm{~m}$.

- Second profile: $100 \mathrm{~m}$ along the center line of the dike.

- Third profile: downstream side of the cofferdam, approximately $400 \mathrm{~m}$ from the dike.

- Fourth profile: $200 \mathrm{~m}$ upstream of the cofferdam.

The results obtained in these profiles are shown in Table 3. 
Table 3. Conductivity and temperature values at selected profiles

\begin{tabular}{|c|c|c|c|c|c|c|c|c|c|}
\hline \multirow{2}{*}{$\begin{array}{c}\text { Depth } \\
\text { (m) }\end{array}$} & \multirow{2}{*}{$\begin{array}{c}\text { Elevation } \\
\text { (m) }\end{array}$} & \multicolumn{2}{|c|}{ Profile 1} & \multicolumn{2}{|c|}{ Profile 2} & \multicolumn{2}{|c|}{ Profile 3} & \multicolumn{2}{|c|}{ Profile 4} \\
\hline & & Cond $(\mu \mathrm{s} / \mathrm{cm})$ & $\mathbf{T}\left({ }^{\circ} \mathbf{C}\right)$ & Cond $(\mu \mathrm{s} / \mathrm{cm})$ & $\mathbf{T}\left({ }^{\circ} \mathbf{C}\right)$ & Cond $(\mu \mathrm{s} / \mathrm{cm})$ & $\mathbf{T}\left({ }^{\circ} \mathbf{C}\right)$ & Cond $(\mu \mathrm{s} / \mathrm{cm})$ & $\mathbf{T}\left({ }^{\circ} \mathbf{C}\right)$ \\
\hline 1 & 725 & 729 & 24.2 & 725 & 24.2 & 727 & 24.1 & 726 & 24.2 \\
\hline 2 & 724 & 729 & 24.2 & 723 & 24.2 & 725 & 24.2 & 726 & 24.1 \\
\hline 3 & 723 & 729 & 24.2 & 726 & 24.2 & 726 & 24.1 & 727 & 24.1 \\
\hline 4 & 722 & 729 & 24.2 & 726 & 24.2 & 726 & 24.1 & 727 & 24.1 \\
\hline 5 & 721 & 729 & 24.1 & 727 & 24.1 & 726 & 24.1 & 727 & 24.1 \\
\hline 6 & 720 & 729 & 23.8 & 726 & 23.8 & 726 & 24.1 & 727 & 24 \\
\hline 7 & 719 & 728 & 23.3 & 727 & 23.4 & 727 & 23.4 & 727 & 23.6 \\
\hline 8 & 718 & 730 & 22.9 & 726 & 23 & 727 & 22.9 & 726 & 22.3 \\
\hline 9 & 717 & 729 & 22.4 & 725 & 22.4 & 724 & 22.1 & 727 & 21.7 \\
\hline 10 & 716 & 722 & 19.6 & 719 & 19.7 & 723 & 19.8 & 722 & 20.3 \\
\hline 11 & 715 & 720 & 19 & 717 & 18.9 & 716 & 18.9 & 720 & 18.8 \\
\hline 12 & 714 & 720 & 17.5 & 716 & 17.7 & 715 & 17.9 & 718 & 18.2 \\
\hline 13 & 713 & 714 & 17.2 & 717 & 17.3 & 716 & 17.6 & 717 & 17.6 \\
\hline 14 & 712 & 718 & 17.1 & 717 & 17.1 & 716 & 17.3 & 718 & 17.1 \\
\hline 15 & 711 & 718 & 17 & 719 & 17 & 717 & 16.9 & - & - \\
\hline
\end{tabular}

Putting the couple representing the conductivity and the temperature in the same graph for different values of the depth, with each profile, is a necessity so that we can have a clear idea on the levels of the zones of infiltration. The temperature, in the case of the existence of a thermal stratification in the reservoir, makes it possible to establish a relation between the temperature of the water of the resurgences and that of the lake; this relation can indicate to which depth of the reservoir the water seeps.

Vertical conductivity profiles, combined with those of the temperature can prove to be decisive, in determining the levels and the grounds where the flow takes place. Indeed, the constant portions of conductivity and temperature indicate the presence of a vertical flow within the lake. Because if the water is stagnant in the lake, the concentration gradient would have had time to disappear and the salinity to homogenize over the entire depth. This is why the importance of the temperature profile appears. In fact, this quantity can be taken into account because it is capable of compensating for difference in density, in other words, the temperature profile must have the same shape as that of the conductivity in order to be able to confirm the existence of a vertical flow. Figure 16 shows the fluctuation in temperature and conductivity as a function of the depths at the chosen locations.
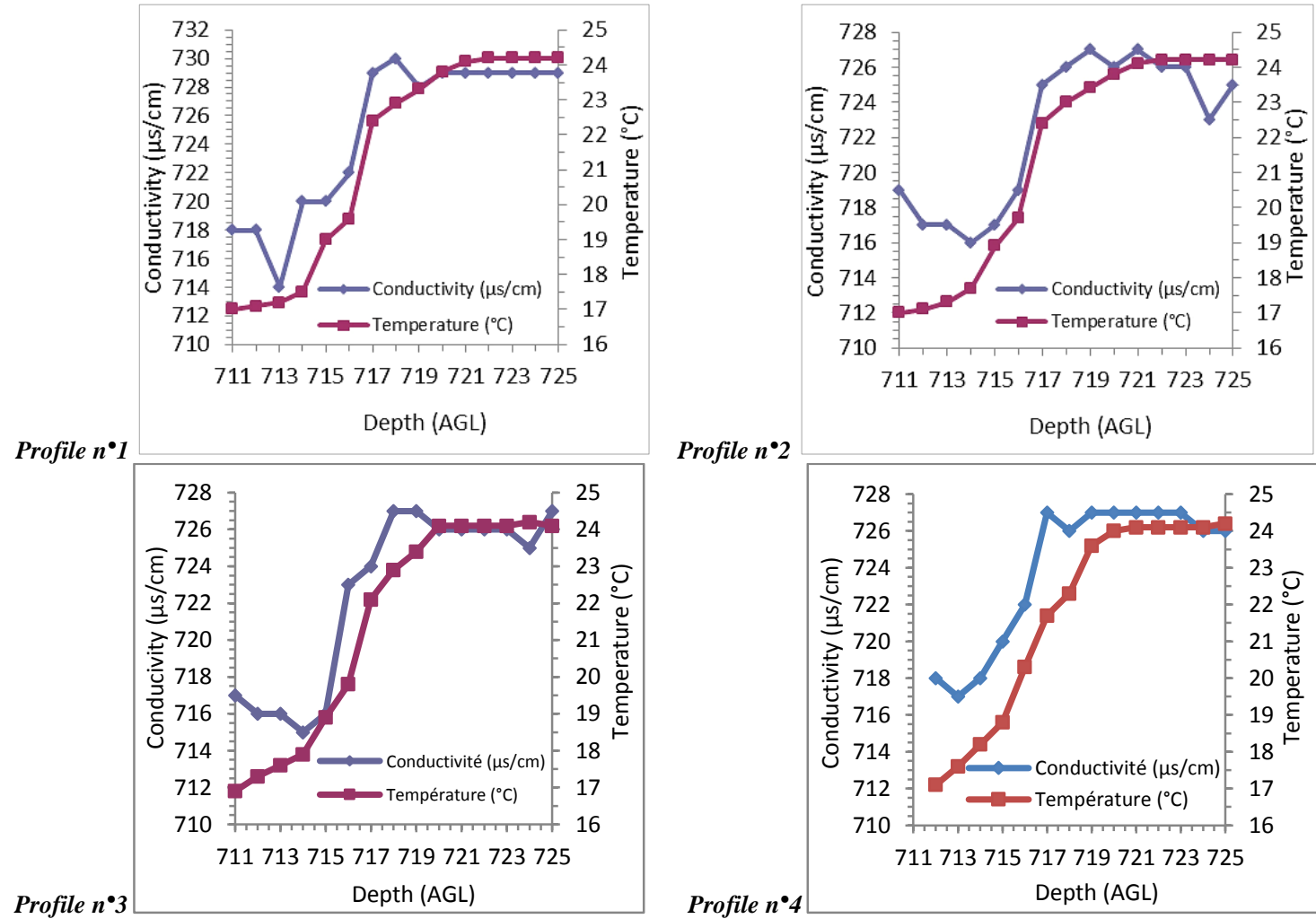

Figure 16. Variation of couple representing the conductivity and the temperature as a function of the water depth at the different profiles 
The four profiles illustrated at figure 16 make it possible to locate the infiltration zone between the depths 714 and $715 \mathrm{~m}$. Indeed, the remarkable difference of the values of temperature and conductivity becomes significant from the $715 \mathrm{~m}$ level and continues up to the $714 \mathrm{~m}$ level. The first profile is recorded to have the largest temperature difference between the levels $715 \mathrm{~m}$ and $714 \mathrm{~m}$, due to its position very close to the vortex.

This difference led the group, to have more precise results, on July 2, 2003 realized a profile between these two levels with a step of $10 \mathrm{~cm}$. Figure 17 shows the couple of conductivity and temperature as a function of the depth at profile $\mathrm{n}^{\circ} 1$.



Figure 17. Fluctuation in temperature and conductivity at profile $n^{\circ} 1$

This representation makes it possible to disclose the levels of water leaks in a range between 714.6 and $714 \mathrm{~m}$. The decrease in temperature by a value equal to $1.3^{\circ} \mathrm{C}$ for a depth of $0.5 \mathrm{~m}$ between 714.5 and $715 \mathrm{~m}$ of levels, can only be explained by a mixture of water due to an additional supply from an annex system which exults at the level of reservoir at this depth.

The conductivity and rhodamine confirm that the origin of the resurgent waters of the reservoir and not of the region's aquifers. This, due to the fact that the sampling of boreholes upstream and downstream of the reservoir gave conductivities close to 2500 and $1695 \mu \mathrm{s} / \mathrm{cm}$ which has nothing to do with the conductivity of reservoir's water, whereas the values of the conductivity at several points of the lake and of the resurgence are very close. We can say that the resurgences' waters come from the lake's dam while the boreholes' waters have no relation, from the point of view of the mineral elements, with the lake's waters. However, the profiles of the temperature and conductivity couple showed the existence of infiltration zones on the right flank within the lake dam.

\subsection{Appearance of the First Vortex}

A series of leak flow measurements was carried out from 16 to 20 April 2003, giving a value of the total flow, during these times, of all the resurgences of $1.5 \mathrm{~m}^{3} / \mathrm{s}$, with a capacity of increase. During this period, a vortex appeared in the basin of the dam. However, its size and location were later detected, after the lowering of the water level in the lake, by divers, it has a diameter of about $1.5 \mathrm{~m}$, at the level of the right bank trough from the reservoir lake. Figure 18 clears the vortex $n^{\circ} 1$ found on the right flank of the lake.

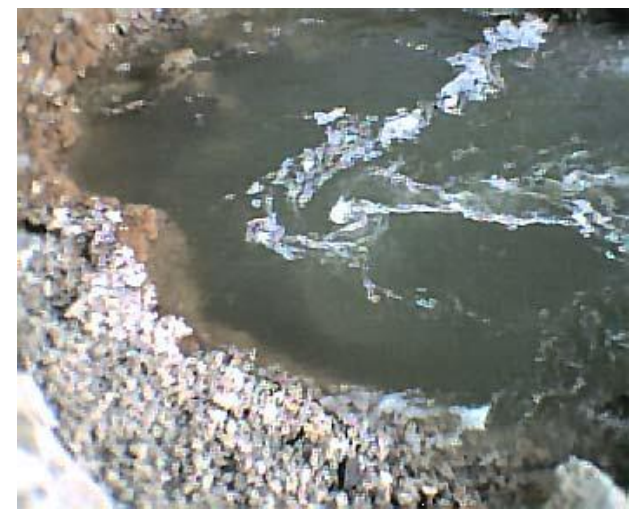

Figure 18. Appearance of vortex $n^{\circ} 1$ 


\section{Second Stage}

\section{- Injection of Fluorescein to Geological Accidents}

During the period from 20 to 23 July 2003, a complementary phase of the previous one, is based on the injection of another fluorescent tracer, it is about the fluorescein at the level of geological accidents known during the work, allowed to limit the losses at the level of the right bank thalweg, because of the fast response of a downstream source which presented a significant flow since July $15^{\text {th }}, 2003$.

\section{- Injection of Fluorescein into the Sinkhole zone}

Doubt at the sinkhole area led the N.A.D.T engineers, on July $22^{\text {nd }}, 2003$, to request an injection of fluorescein in this area but the monitoring of the arrival of the tracer, carried out for 36 hours, did not reveal anything.

\section{- Treatment of Leaks Generated by the Vortex $n^{\circ} 1$}

Foreign experts and engineers from N.A.D.T, during the period from 21 to 23 of October 2003, proposed a methodology for the urgent treatment of vortex leaks No, 1. This methodology is based on the following two points:

Construct an access road on the rip-rap from the main road to the adjacent lake vortex location allowing access to it as shown in Figure 19.

$>$ Construct a platform around the vortex to the $723 \mathrm{~m}$ level of $100 \mathrm{~m}$ long and store rip-rap materials, (gravel, sand and clay).

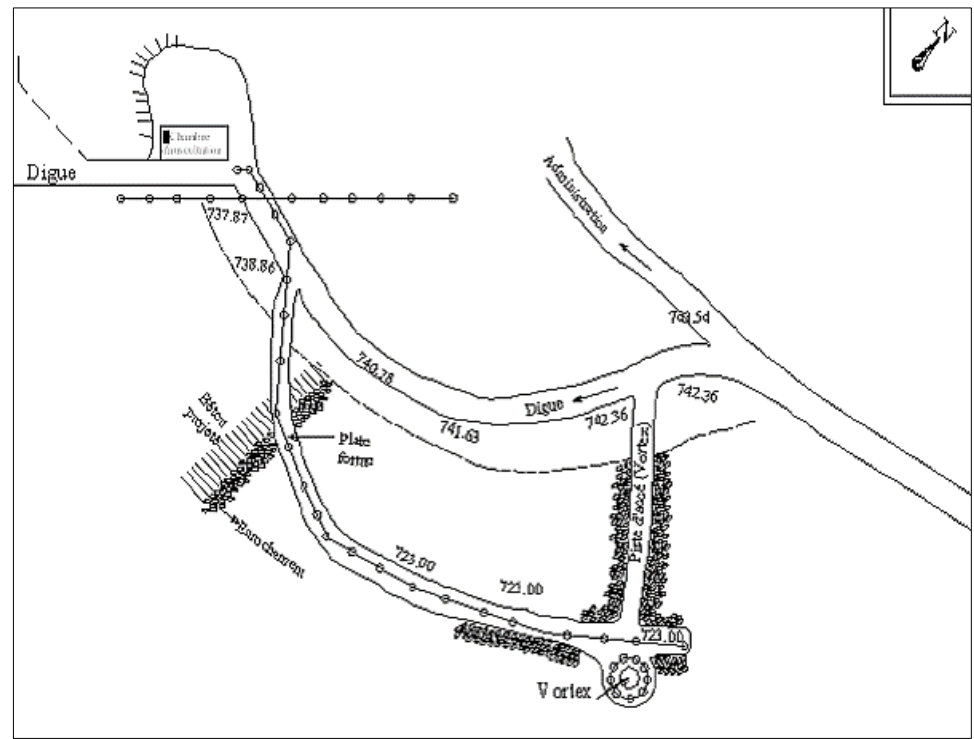

Figure 19. Approximate diagram of sealing and sealing work on vortex $n^{\circ} 1$

The closure of the vortex $n^{\circ} 1$ was achieved by the injection and filling of the vortex hole during the month of March 2004, by an expansive chemical consisting of polyurethane. This chemical, which is a mixed cement, is manufactured with a wide variety of textures and hardness, is used to seal and seal cracks (Figure 20).

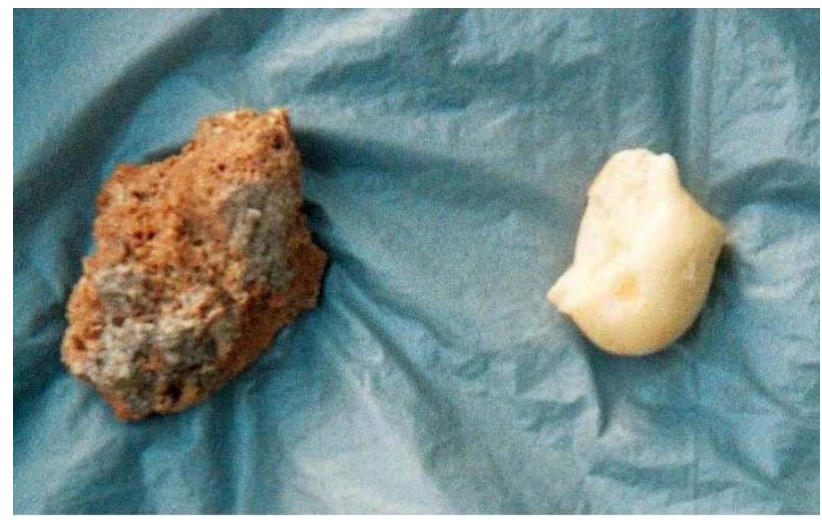

Figure 20. Polyurethane product used to close the vortex $\mathbf{n}^{\circ} 1$ 
Injection holes on a semicircular line were made from the platform built around the vortex. Figure 8 also illustrates the injection holes. It has been recommended that the vortex be squeezed in a complete circle to ensure that all vortex groundwater pipes and cavities are filled and plugged. Subsequently, it will be necessary to rebuild the clay carpet above the closed vortex and it will be protected by sand filters below and above the carpet $200 \mathrm{~mm}$ thick. The platform encircling the vortex will be partially excavated, maintained and protected by rip-rap, as well as the depression inside it will be filled by ordinary embankment of the same nature as the embankment of the platform then covered also by gravel and rip-rap. The completion of sealing work at the first vortex level would be just the beginning to start other work because the site became highly vulnerable to water leakage and its resolution lies in the determination, on the scale the lake and the banks, all the formidable places and strengthen them appropriately by the most suitable and most indispensable materials. The monitoring of the piezometer allowed, from the first to the 31st of March 2004 and after the closure of the vortex $n^{\circ} 1$, to record a decrease of the level of water of two meters in a drilling located on the right bank. However, this encouraging result must be persisted effectively with the raising of the level of the water body.

\subsection{Flow Measurements Downstream of the Hammam Grouz Dam}

The existence of underground thermal springs downstream of the dam, and more precisely at the level of the downstream flank of the right bank, contributes to an additional flow rate which is added to the flow rate of the lake leaks, which makes the total flow rate random leaks measured at certain locations. During the month of July 2004 , when the lake's elevation was $716 \mathrm{~m}$, the average downstream cumulative flow is measured at approximately $7501 / \mathrm{s}$, while the actual dam leakage calculated according to the variation of the of the lake, the capacity curve and the hydrological data, are estimated at $540 \mathrm{l} / \mathrm{s}$.

The decrease in the piezometric level of the borehole and the difference between the flow rate measured downstream of the dam and that of the actual reservoir leaks confirms that the water leaks have persisted, and it is deduced that there are other water entry points most likely through the cracked limestones of the right bank of the lake.

\subsection{Veil of Injections Performed}

The strong hydraulic continuity between the lake's waters and the waters of the various resurgences led, the concerned services, to opt for the making of an injection veil. Indeed, an injection veil was produced during the August month of 2004 on the right bank and extends from the vortex zone to the dam stop. The figure $n^{\circ} 21$ shows the injection boreholes carried out at the right bank. The materials injected into the boreholes produced, during the production of the sealing veil, have resurfaced as a grout at the drainage gallery and also at the resurgences located downstream of the dike, this shows that the veil intercepts the groundwater circulation going to the dike's foundation and downstream from the right bank.



Figure 21. Location of the boreholes of part of the injection veil

The sail is sealed by filling the cavities encountered in the boreholes by gravity fall of the gravel through their holes, the cavity is filled with a grout of cement, sand and water, but the question that arises, is this veil the most optimal solution or the problem arises with the choice of the materials used or even the quality of the work carried out. Despite the veil sealing made, the waters continued to escape from the lake and the doubt of the existence of the other defective places opens and the rate of leaks, when the level of the water in the lake rise, may increase, over time, which again disrupts the management and operation of this structure. 


\subsection{Increased Dam Capacity and Emergence of Sand}

During the first four months of 2005 and after very heavy rainfall (snow and rain), the capacity of the dam increased in a very remarkable way, from $2.86 \mathrm{Hm}^{3}$ in December 2004 to $9.24 \mathrm{Hm}^{3}$ in January 2005. This increase to continue until the month of May of the year 2005 reaching a capacity of $40.10 \mathrm{Hm}^{3}$. This result has led to a resurgence of sand at some of the resurgences downstream of the dike due to the increase in hydrostatic pressure created by the rise of the water level in the lake. Figure 22 illustrates the gushing of the sand.
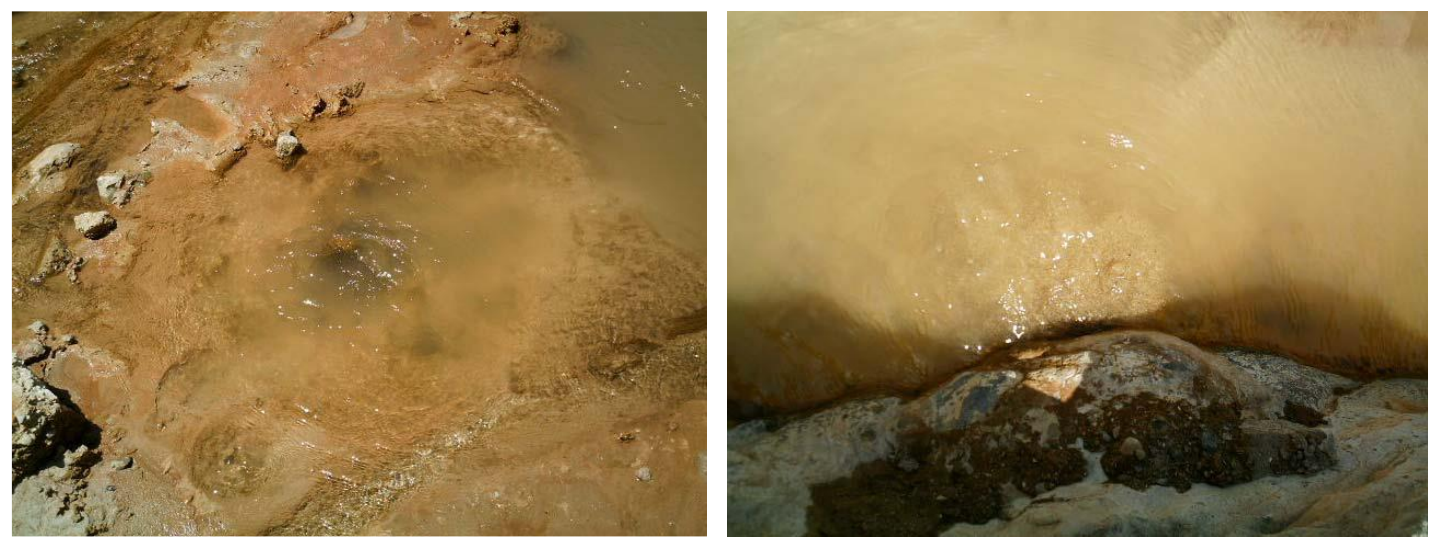

Figure 22. Sand downstream of the dam

This appearance is due to a migration of earthy particles either clay or karst fissure joints what is called the Renard phenomenon. However, it is confirmed that this sand contains a percentage of that filled in the first sinkhole and another of the filter layers put in the second sinkhole is not yet guaranteed. This sand spout testifies that the first consolidation treatment realized during the construction of the dike, was modified naturally (under the effect of the underground infiltrations) or it was not perfect. This spurt of sand will also lead to an enlargement of the sections of the preferential paths of the water. Consequently, we witness an increase in the volume of water lost. However, the problem that arises is the influence of this escape of the sand when the level of the lake would be maintained, a sufficient time, at a value very close to that of the normal level of the reservoir.

\subsection{Appearance of the Second Vortex}

In November 2007, following the remarkable narrowing of the lake of the reservoir, a second larger vortex appears at the right bank of the Hammam Grouz reservoir and consists of two openings very close. Figure 23 elucidates the location of the new vortex in the lake.

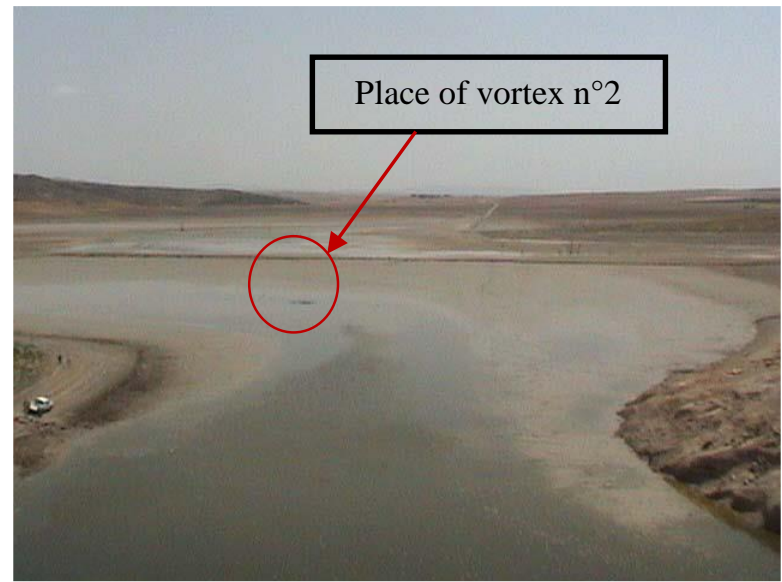

Figure 23. Appearance and location of the vortex $n^{\circ} 2$ in the lake of Hammam Grouz dam

Following this appearance, we can think of the reactivation of the area of the old vortex where the thickness of the alluvial cover does not exceed a few meters. As a result, the clay carpet collapsed at the opening of the old vortex and above the new one. The Figure 24 shows the Diagram of a longitudinal section of the vortex 02 before its sealing. 


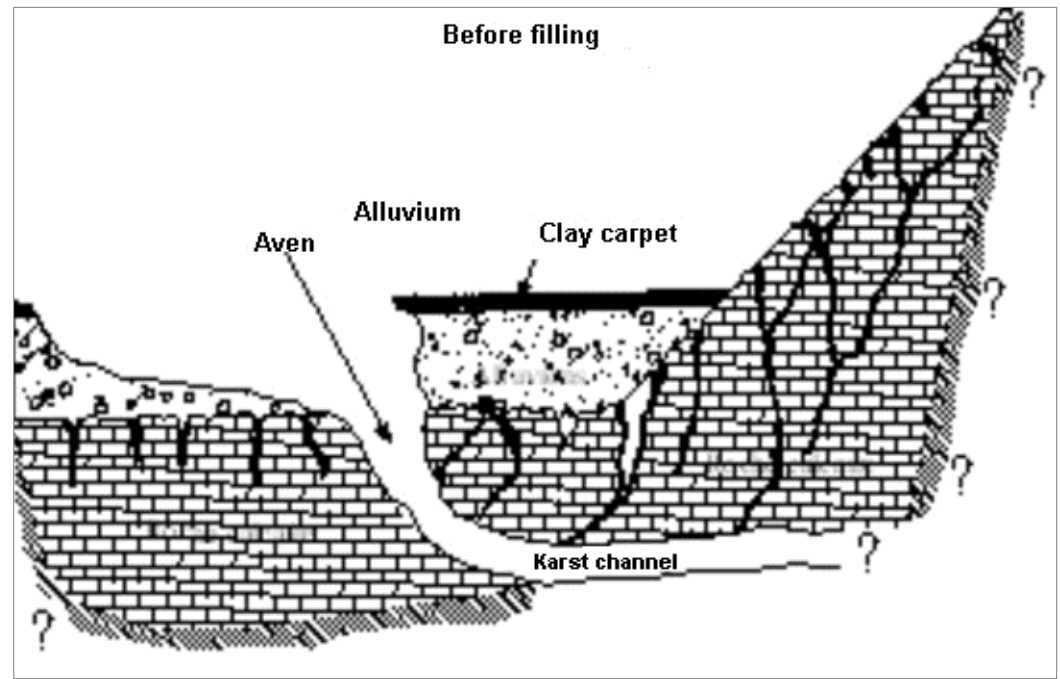

Figure 24. Diagram of a longitudinal section of the vortex $n^{\circ} 2$ before its sealing

Water losses from the reservoir through the right flank have increased significantly in the direction of downstream resurgences. This last problem caused the emptying of the reservoir, and since, the capacity is of the order of 0.002 $\mathrm{Hm}^{3}$, whereas during the first three months of the year 2008 (January, February and March), the restraint is practically at dry. This situation has led the departments concerned, to really think about solving the problem was regenerating at this place.

\subsection{Sealing of the Vortex $n^{\circ} 2$}

The appearance of the second vortex accompanied by the activation of the old aven considerably increased the water losses of the reservoir, and therefore the filling of this zone is essential. The recommended method for closing this area is as follows:

- Remove alluvial deposits to limestone over an area determined by the quality of the surrounding rock;

- Purge aven openings and karst canal entrances;

- The limestone base and all existing cracks therein are properly purged of all fillings and rinsed with water;

- Fill with concrete the entrances of both avens;

- Place a reinforced concrete slab $0.5 \mathrm{~m}$ thick (See Figure 25).

- Put the excavated materials back on the slab by making a permanent compaction;

- Make, as long as the final layer, the clay carpet having the characteristics identical to those of the carpet at the bottom of the reservoir.

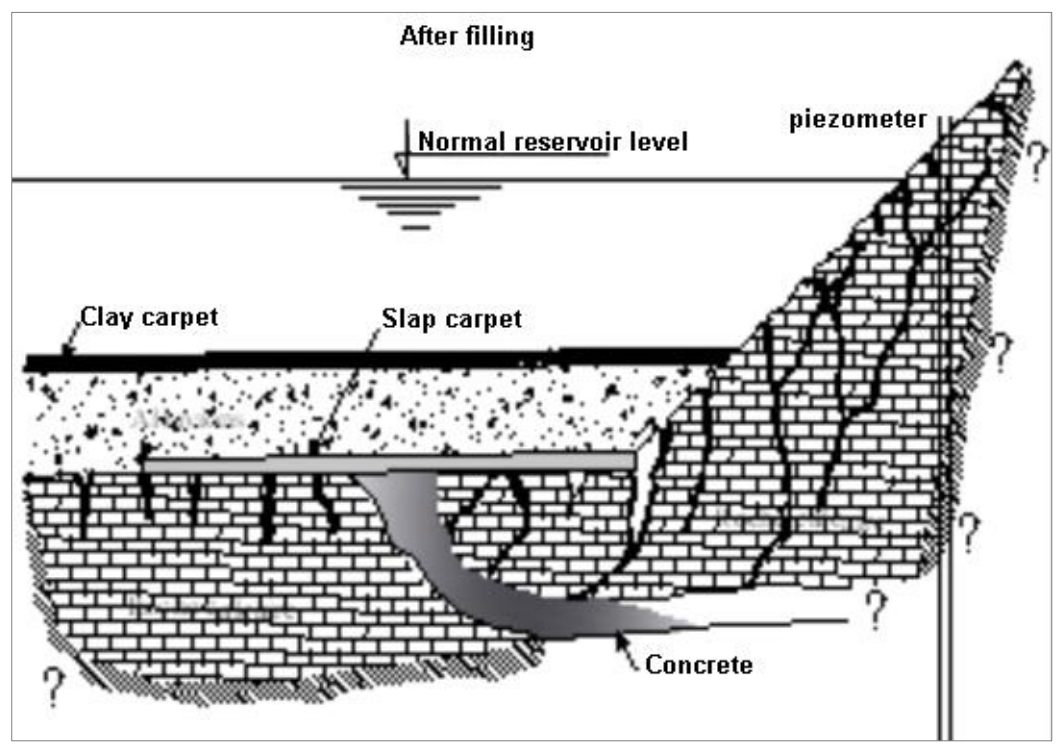

Figure 25. Diagram of a longitudinal section of the vortex $n^{\circ} 2$ after its sealing 
Too much restoration work has been carried out at the Hammam Grouz dam, but the problem has not been addressed by these origins and the guarantee that other infiltration areas will not be secured. The sealing treatment of a karstic site, vulnerable to the appearance of sinkholes and siphons, by loose materials that do not have the same characteristics of the site generates, over time, unforeseen events that threaten the stability and amount of water stored. Indeed, the Renard phenomenon and the deep karstic dissolutions can increase the sections of the underground water flow paths. The sealing works carried out have given satisfactory results but they remain far from the ambitions of the services concerned. Indeed, the closure of the 1st vortex, the veil of injection, carried out on the flank must, and the filling of the second vortex did not solve the definitive problem and the waters would persist to escape from the lake of the dam at fluctuating flows, to the course of time, with the variation of the water body.

Doubt at the geological water tightness of the lake, the foundation of the dike and especially the right bank, this book, remains everyone's concern and especially during the occurrence of floods where there would be a rapid rise in level of the water level above the bottom of the bowl.

\subsection{Study of Surface Flows, Hydraulic Balance and Leakage Rates at Hammam Grouz Dam}

\section{The Precipitations}

Knowledge of the spatio-temporal variations of precipitation is necessary to obtain at least a relationship which connects these with the flows recorded at the hydrometric station and therefore we can reduce the volume of the tributary returning to the basin of the dam.

\section{Average Annual Precipitation}

The monitoring of the precipitation at the rainfall station of Hammam Grouz, over a period of 30 years (1987 / 88 2016 / 17), made it possible to extract the two extremely wet and dry years, these are the hydrological years 2002 / 2003 , with a maximum value of $668.8 \mathrm{~mm}$ and 2016-2017, with a minimum value of $180.5 \mathrm{~mm}$. Figure 26 represents the fluctuation of the average annual precipitation during the aforementioned period.

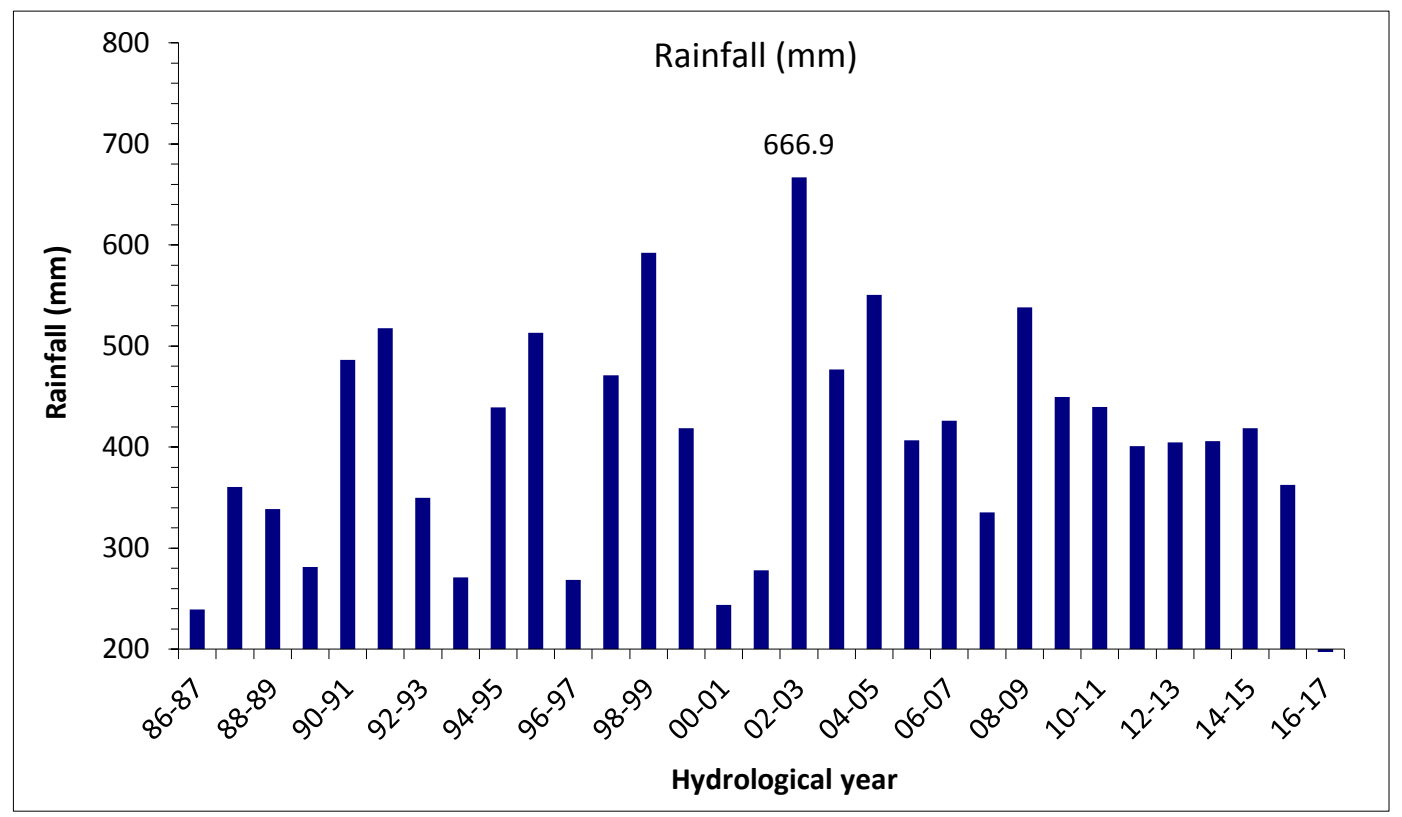

Figure 26. Variation in average annual precipitation during the period from 1987/1988 to 206/2017 at rainfall station of Hammam-Grouz dam

The irregularity and the phenomenon of fluctuation in the distribution of precipitation at this rainfall station obey the climatic character of eastern Algeria, which constitutes the region, on a regional scale, the wettest and most varied climatically.

\section{Monthly Variation in Precipitation at Hammam Grouz Dam Station}

To illustrate the variable nature of the rainfall regime, it is necessary to analyze the variations in monthly precipitation over a more or less long period. For this, we are based on the monthly precipitation data recorded at the Hammam Grouz station since its impoundment until the 2016/2017 hydrological year. Figure 27 shows the average monthly variation of rain during the period from 1987/1988 to 2016/2017. 


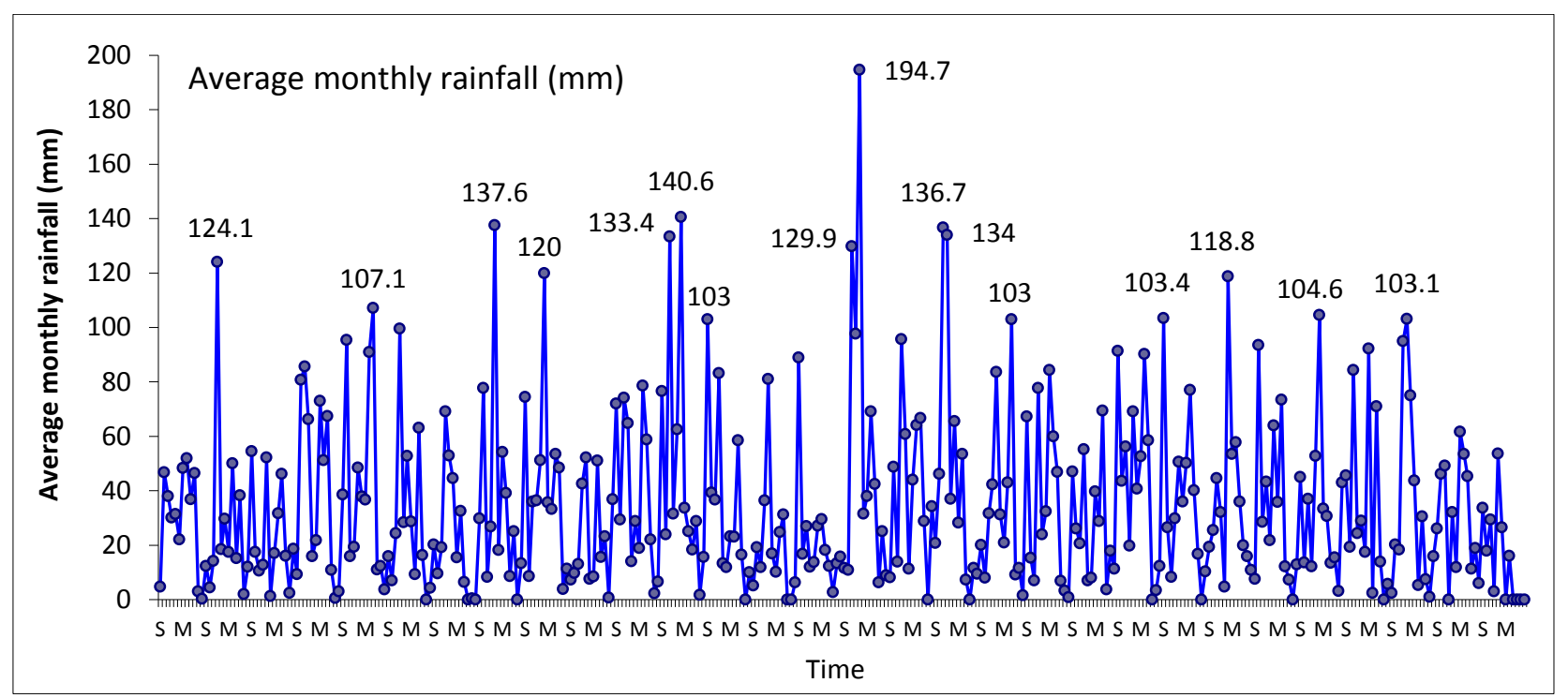

Figure 27. Average monthly variations in precipitation at the Hammam Grouz rainfall station (1987/88 -2016/2017)

The average monthly rain recorded during this period is around $35 \mathrm{~mm}$. However, the largest quantities fall successively in the winter and spring seasons. In fact, the irregularity of precipitation results in dry years with a maximum of monthly rains which does not exceed $54 \mathrm{~mm}$, this is the case for 2016/2017 hydrological year where the maximum quantity is in January it is $53.7 \mathrm{~mm}$. As it can translate into exceptional rainy years. This is the case for the year 2002/2003 (annual total: $666.9 \mathrm{~mm}$ ) where the amount of rainfall in January, around $197.4 \mathrm{~mm}$, exceeds the annual total for $2016 / 2017$ which is $180,5 \mathrm{~mm}$. During this period, fluctuations are observed at peak precipitation exceeding $100 \mathrm{~mm}$. Indeed, these values can put the body of water beyond its normal level and consequently the appearance more of the problem in question. This makes it essential to represent the hydrological years of these peaks and especially the year when the largest peak of $197.4 \mathrm{~mm}$ is observed, this is the year 2002/2003. Figure 28 represents the monthly variation of the rain at the rainfall station of the Hammam Grouz dam in 2002/2003 hydrological year.



Figure 28. Monthly fluctuation of the rain at the rainfall station of Hammam-Grouz dam during the hydrological year (2002-2003)

These rains, significant in this semi-arid area, quickly brought the water level in the dam, and for the first time since its impoundment, to a level higher than normal. What put all the elements of the dam (the dike, the banks, the bottom of the lake, the piezometers, the Tasso meters etc.) under the most important pressure today. This pressurization revealed water resurgences downstream of the dam and emerged the lower gallery. Indeed, because of the importance of the water losses recorded, the volume of water stored in the bowl underwent rapid lowering. This lowering is due to the maneuvers of the drain valves and the high leakage rates. 


\section{Flow Rates}

\section{Annual Average Flows}

The use of the average annual flows measured at the Oued Athmenia hydrometric station located about 1100 meters upstream of the dike during the period from 1993/1994 to 2004/2005 can help to better estimate the annual volume entering the basin of the dam and then carry out a comparative study between this volume and the volume leaving the lake in order to deduce the annual volume lost by leaks. Figure 29 shows the variation of the average annual flow during the aforementioned period. This period was chosen because of the appearance, for the first time, of resurgences with high flow of water downstream of the dike that is to say that the dam was in operation.

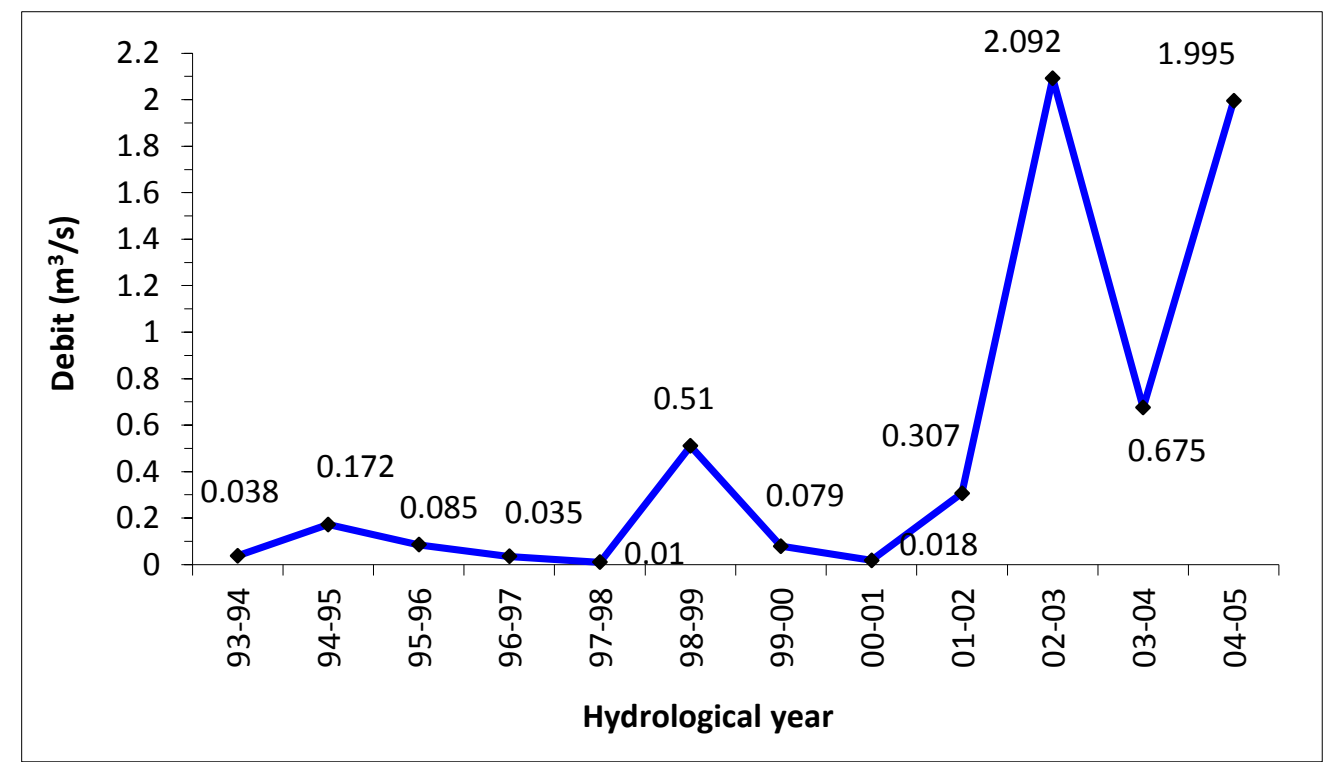

Figure 29. Fluctuation of the average annual flow at the hydrometric station of Athménia River located upstream near the lake of Hammam Grouz dam, Algeria

At first glance at this representation, two important annual average flow rates of 2.092 and $1.995 \mathrm{~m}^{3} / \mathrm{s}$ are recorded successively in the years $2002 / 2003$ and $2004 / 2005$. While the average annual flow rate is equal to $0.5013 \mathrm{~m}^{3} / \mathrm{s}$, i.e. a contribution of about $15.896 \mathrm{Hm}^{3} /$ year which represents $1 / 3$ of the total capacity of the dam. The highest flow value coincides with the 2002/2003 hydrological year, which was the rainiest, see Figures 26 and 27.

\section{Monthly Average Flows}

Placing the graph of average monthly flows during the selected period may help further understanding the relationship between monthly average flows and average monthly rainfall over the same period. Figure 30 shows the average monthly debits from $1993 / 1994$ to $2004 / 2005$.

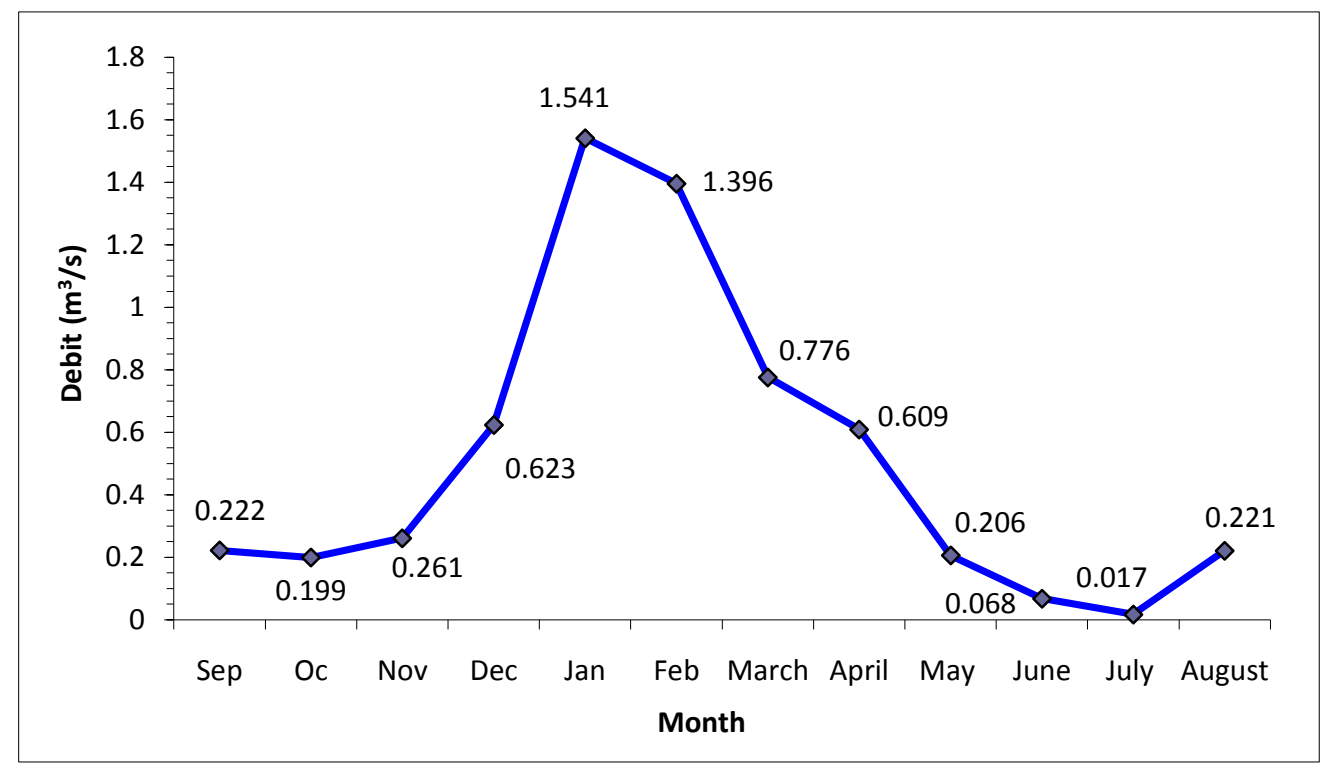

Figure 30. Average monthly debits, 1993/94-2004/05 
The minimum flow rate is of the order of $0.017 \mathrm{~m}^{3} / \mathrm{s}$, recorded in July. However, the highest average monthly flow values are recorded successively in January $\left(1.541 \mathrm{~m}^{3} / \mathrm{s}\right)$, February $\left(1.396 \mathrm{~m}^{3} / \mathrm{s}\right)$, April $\left(0.776 \mathrm{~m}^{3} / \mathrm{s}\right)$ and December $\left(0.623 \mathrm{~m}^{3} / \mathrm{s}\right)$.

\section{Average Daily Hydrometric Flow Rates}

The exceptionality of the first value makes it necessary to monitor monthly measured flows during the year, because during this year the problem of water leaks appeared and grew. Figure 31 shows the variation of the monthly discharges measured at the Oued Athmenia station in 2002/2003.

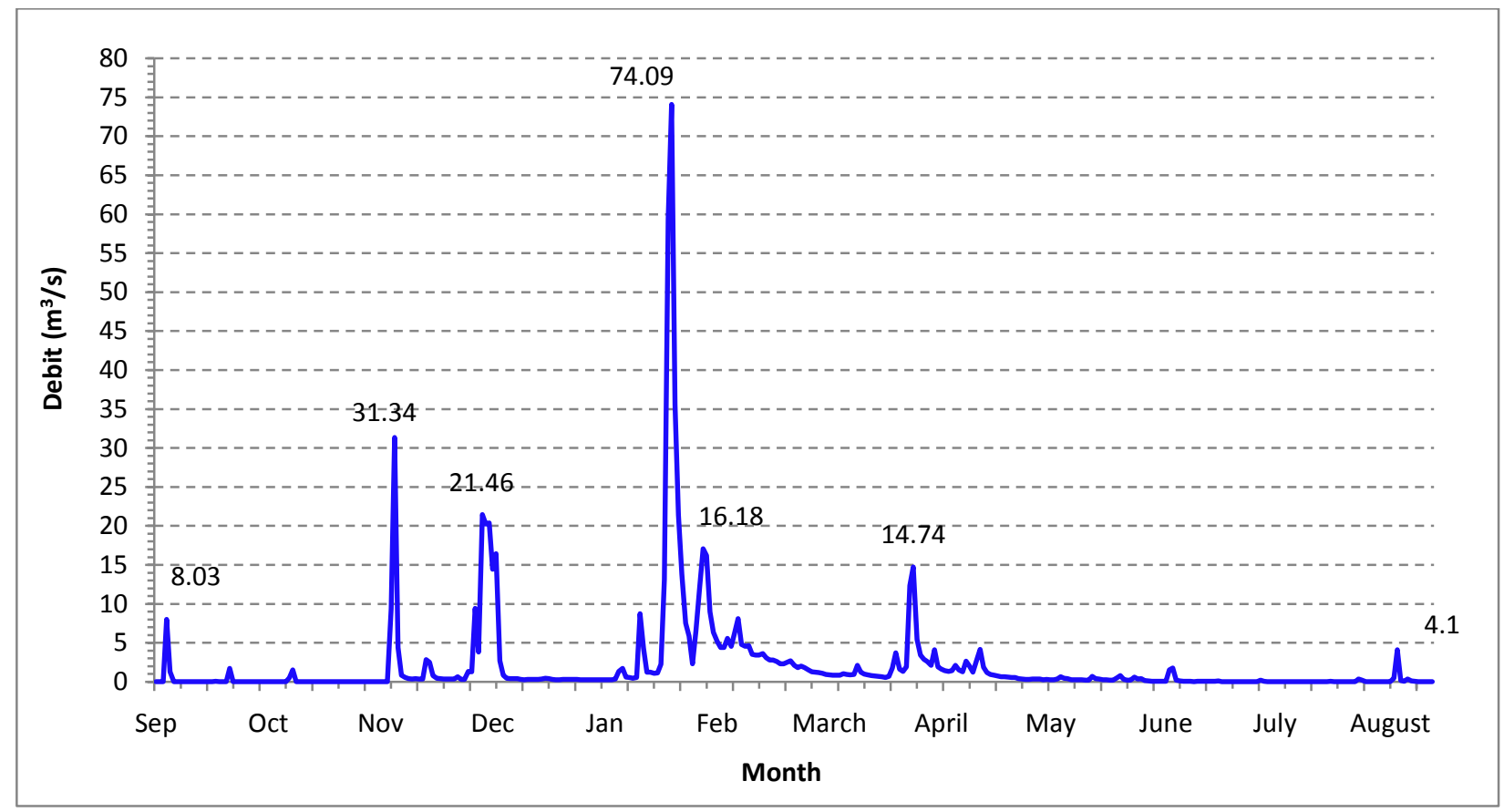

Figure 31. Fluctuation in daily debits for exceptional year 2002/2003

This representation makes it possible, in an explicit way, to record daily average flows of large floods not uniformly distributed during this year, which gave them a random character.

\section{The Analysis of this Temporary Irregularity}

The analysis of this temporary irregularity, during this year, can also go directly to the largest value of the average monthly flow recorded on January 26 which is equal to $74.09 \mathrm{~m}^{3} / \mathrm{s}$, this latter corresponds to the maximum value of precipitation which is around $194.7 \mathrm{~mm}$ out of an annual total of $668.8 \mathrm{~mm} /$ year. The second observation is the four floods observed on November 8, 2002, December 3, 2002, February 4, 2003 and April 5, 2003 successively reaching $31.34,21.46,17.09$ and $14.74 \mathrm{~m}^{3} / \mathrm{s}$. These flow values coincided with the average monthly precipitation values recorded 129.9, 97.9, 31.6 and $69.2 \mathrm{~mm}$.

\section{Rain-flow Relationship (Case of the Exceptional Year 2002-2003)}

In order to find the response of the watershed in terms of flow and its relation to the magnitude and irregularity of the precipitation recorded, we have represented the variation of the rain-flow couple during the appearance of the most significant floods. Figure 32 shows the fluctuation of the rain-flow couple on the days of occurrence of major floods. These figures show that the response of the watershed in terms of average daily flow is not simultaneous with rain in most cases. Indeed, for the months of November, January and April the response of the watershed (the time of arrival of the average daily flow at the lake of the dam for maximum rain) is reached in one day while for the months from February and December the response is completed in 3 days for the first and a quick response (less than a day) for the last. However, the flow arriving at the lake of the dam obeys the rains that fell across its watershed.

This sudden arrival led to a rapid filling of the bowl, which led to a disturbance of the balance already established between the lake and the aquifers of the region. This imbalance can, due to the repetitions, put the banks under stresses which generate an extraction and / or a dissolution of the materials of the karstic joints. 

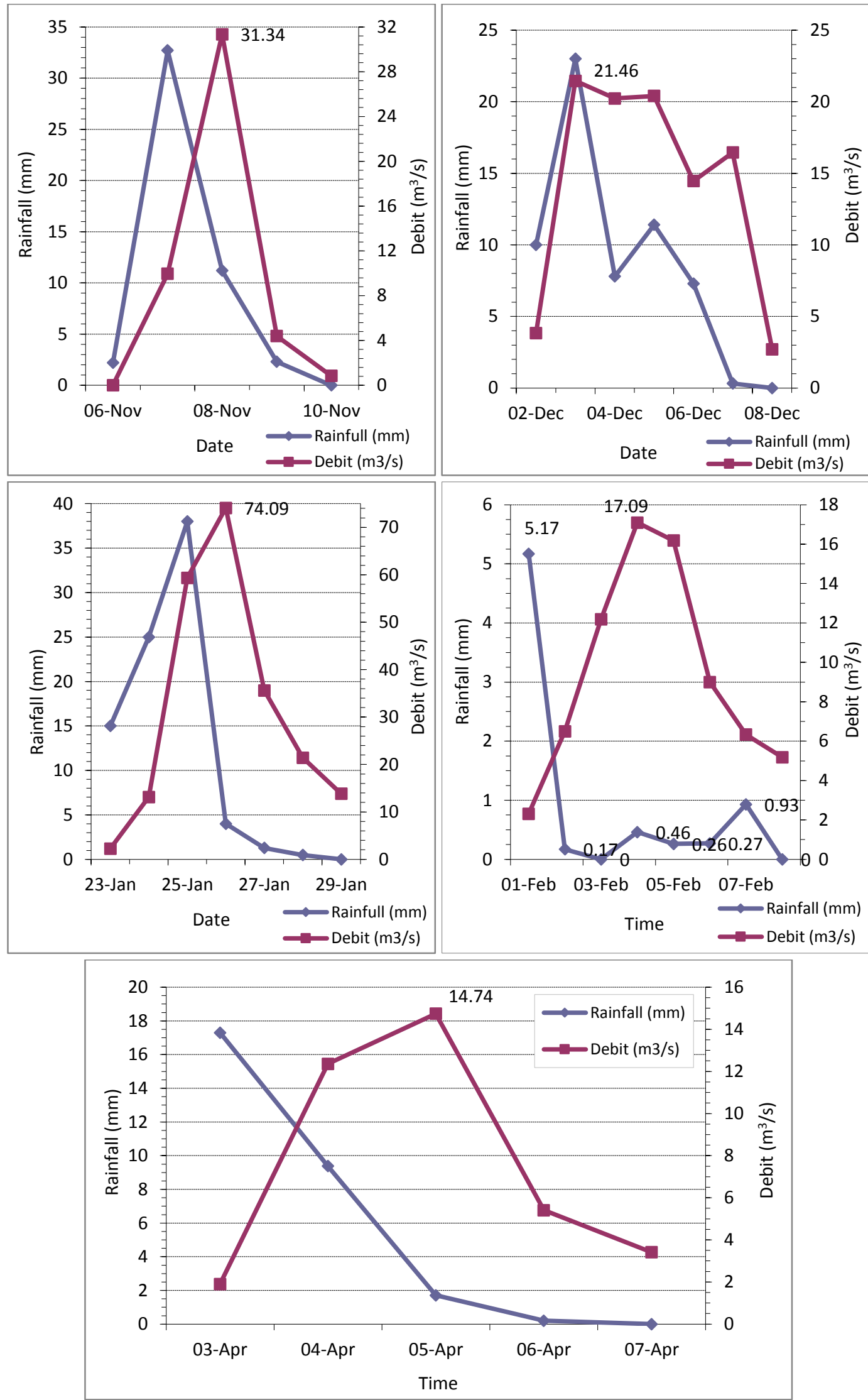

Figure 32. Average daily rain-flow couple during the exceptional year 2002/2003

\section{Relation of the Actual Flow Entering the Bowl and Contribution of the Hydrometric Station}

To obtain a relation which connects the flows recorded at the hydrometric station and the flows entering the basin of the dam taken from the hydraulic balance, we have represented on Figure 33 the variation of the Q entering the basin according to $\mathrm{Q}$ recorded at the hydrometric station. 


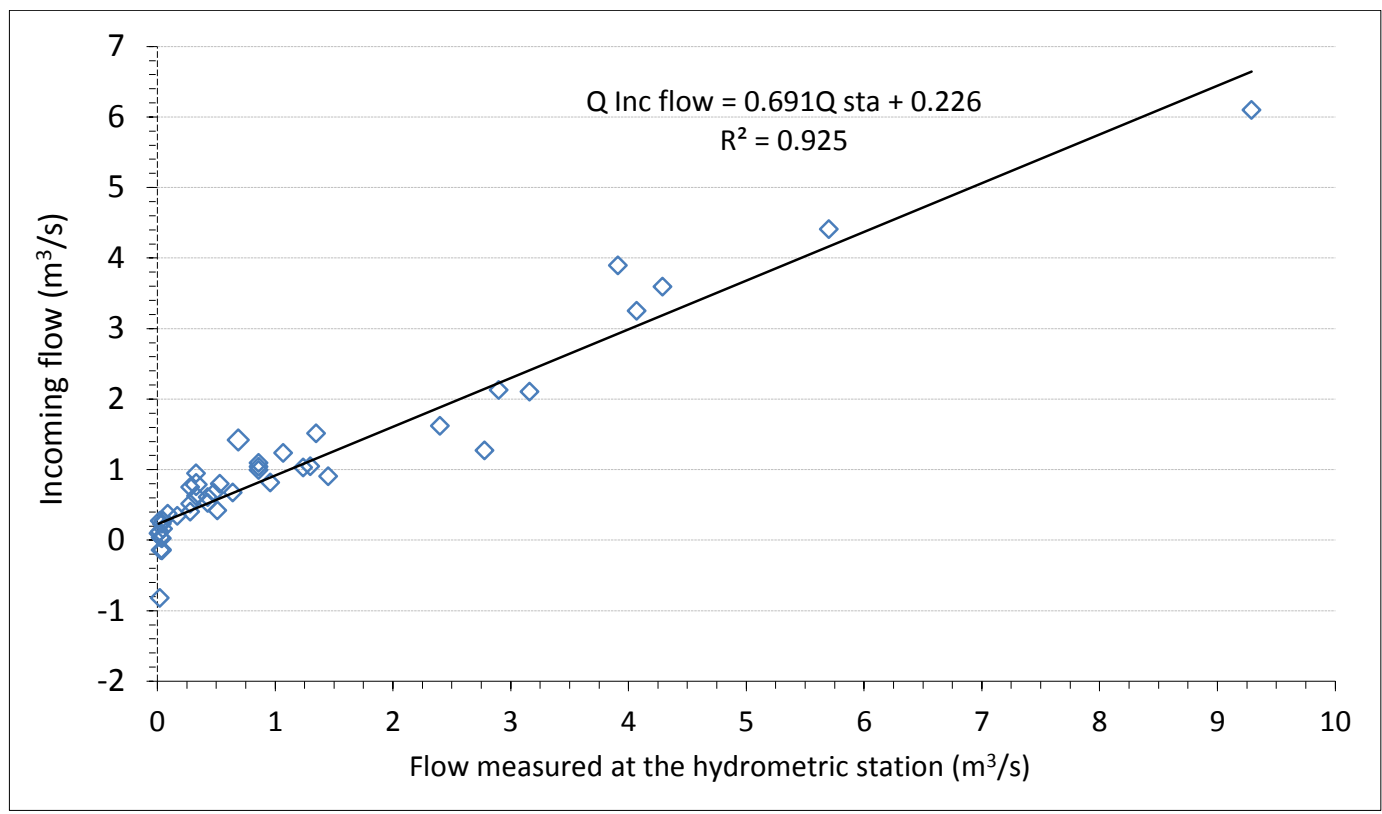

Figure 33. Variation of the real incoming flow in the bowl as a function of the flow recoded at the hydrometric station

It should be noted that a percentage of 7.5 of the variance is not represented by this correlation, which proves that it is not only the flow of the tributary which passes through the hydrometric station which feeds the basin of the dam. Negative inflows have been observed, which indicates that there is a decrease in the level of the water level in the basin of the dam that is to say that the quantity of water leaving the basin exceeds that entering.

\section{Relation of Leak Rate and Actual Flow Entering the Bowl}

The search for a relationship, which links the flow of the leaks and the actual input into the bowl, led to the drawing of Figure 34.

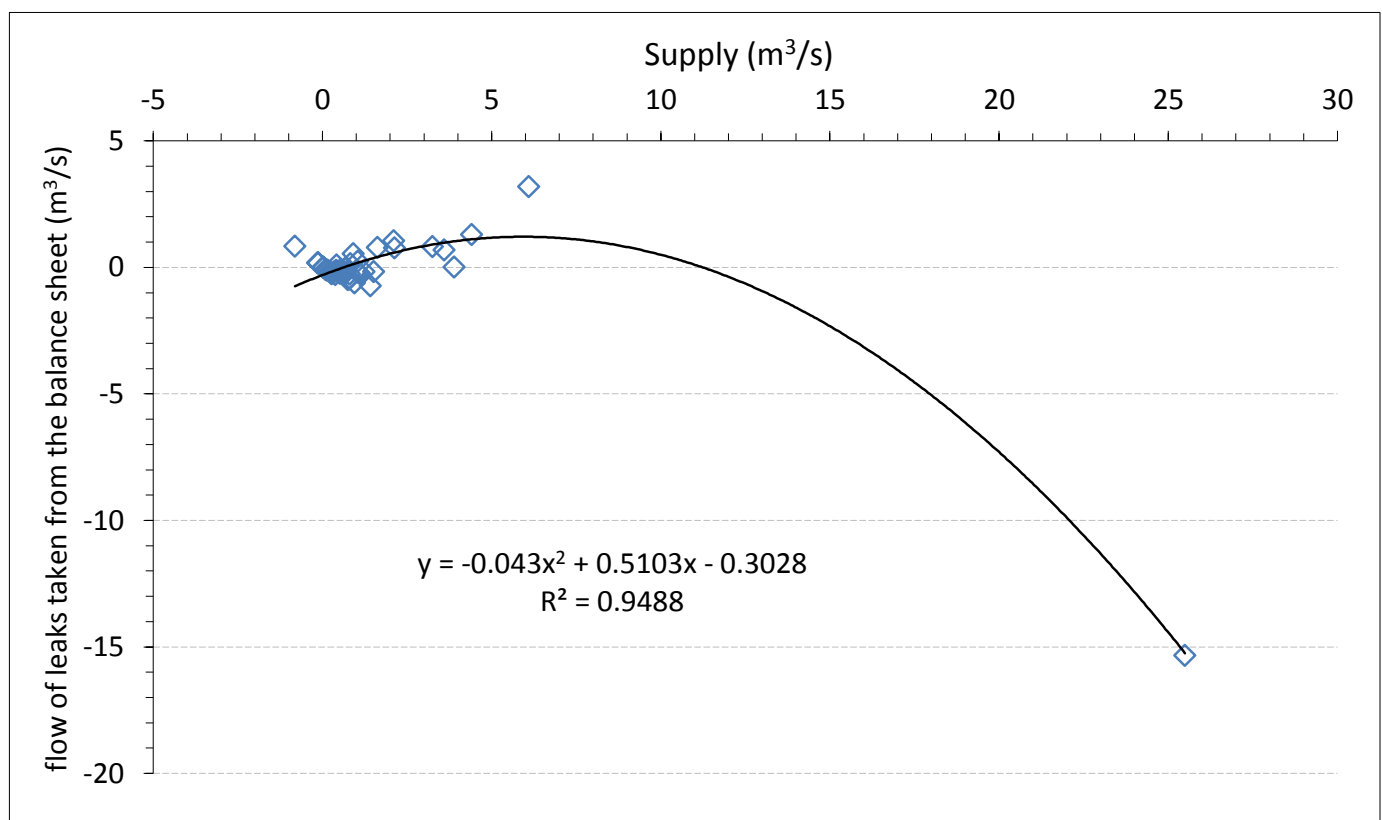

Figure 34. Variation in the leakage rate deducted from the hydraulic balance as a function of the entering flow of Hammam Grouz dam, Algeria

Negative flow values show that the inflow per tributary deducted from the daily water balance of the dam is greater than the inflow recorded at the hydrometric station.

\section{Measured Leakage Rate}

The daily monitoring of the leak flow at the Hammam Grouz dam, during a period from 22/04/2003 to 31/08/2005, made it possible to represent the variation of this flow over time. Figure 35 illustrates this variation. 


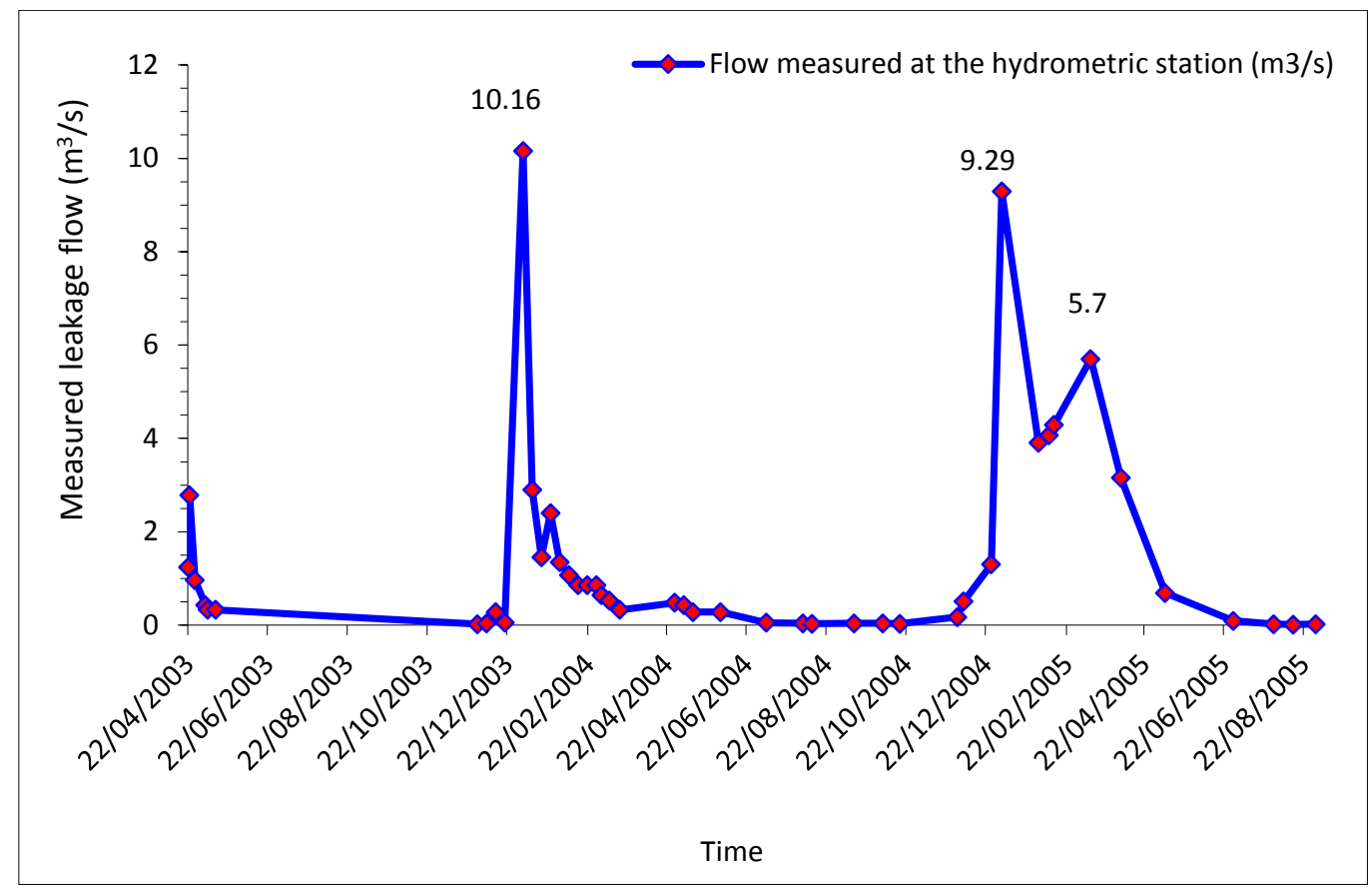

Figure 35. Variation over the time of the flow rate of water leaks measured downstream of Hammam Grouz dam

This representation makes it possible to extract the maximum peak leakage values recorded on 23/04/2003, $14 / 02 / 2004$ and $08 / 05 / 2005$, which are successively of the order of $1.414,1.279$ and $1.14 \mathrm{~m}^{3} / \mathrm{s}$.

\section{Relation of Leakage Flow Measured and Levels of Water in the Lake}

In order to obtain a relationship that relates the measured leakage rate and the level of the lake in the lake, we will represent the first one according to the second one. Figure 36 shows the variation in the flow of leaks as a function of the water level at the Hammam Grouz dam for grades ranging from 713 to $719 \mathrm{~m}$.



Figure 36. Variation of the leaked flow as a function of the water level for heights less than $718.5 \mathrm{~m}$ at Hammam-Grouz dam

The values of the measured leakage rate over time for ratings between 713.5 and $718.5 \mathrm{~m}$ are in the range of 0.4 to $1.3 \mathrm{~m}^{3} / \mathrm{s}$ and vary linearly with the rise of the body of water explaining $88 \%$ of the variance. Figure 37 elucidates the change in leak flow as a function of the lake's elevation for ratings between 720.5 and the normal reservoir level. 




Figure 37. Variation of the leaked flow as a function of water level for heights between $720.5 \mathrm{~m}$ and the normal level of the reservoir

The values of the leakage rate measured, over time, for ratings between 720.5 and $727.5 \mathrm{~m}$, are in the range of 0.58 to $1.415 \mathrm{~m}^{3} / \mathrm{s}$. However, the decrease in the leakage rate for dimensions greater than $720 \mathrm{~m}$ can be explained by the waterproofing work carried out, but for levels close to that of the normal reservoir level (N.R.L), leakage rates, although they have decreased as a result of construction work. They are still important, which can lead to unforeseen situations when there is a rise in the water level. Indeed, the phenomenon of water leaks in the dams has become hazardous if the flow of leaks increases, over time, for the same level of water in the lake.

\section{Fluctuation of the Pair Representing the Water Level in the Lake and the Volume of Water Stored During the Last Three Hydrological Years}

To highlight the effectiveness of the sealing works carried out since the appearance of the phenomenon of water leakage at the Hammam Grouz dam. While relying on the necessary and available data, we begin a short description by which we will try to reveal what has been done and participate in the preservation of this water heritage. The follow-up over time of the torque representing the volume in the lake and the water level can give global information on the state of the water tightness of the lake bottom, the foundation of the dike and the banks. Figure 38 illustrates the variation of this pair during the last three hydrological years.



Figure 38. Variation over the time of the couple of water level in the lake and the filling volume at Hammam Grouz dam during the period from 2014 to 2017

The first observation to be learned is that the fall of the couple (water level-stored volume) has become gradual. That is to say, the gradient is less important than that obtained during the appearance of the phenomenon of leaks of water. However, the storage capacity remains below $1 / 3$ of the theoretical one, which proved that the water leaks persisted. Figure 39 illustrates the Variation in the water level at Hammam Grouz dam since its impoundment. 


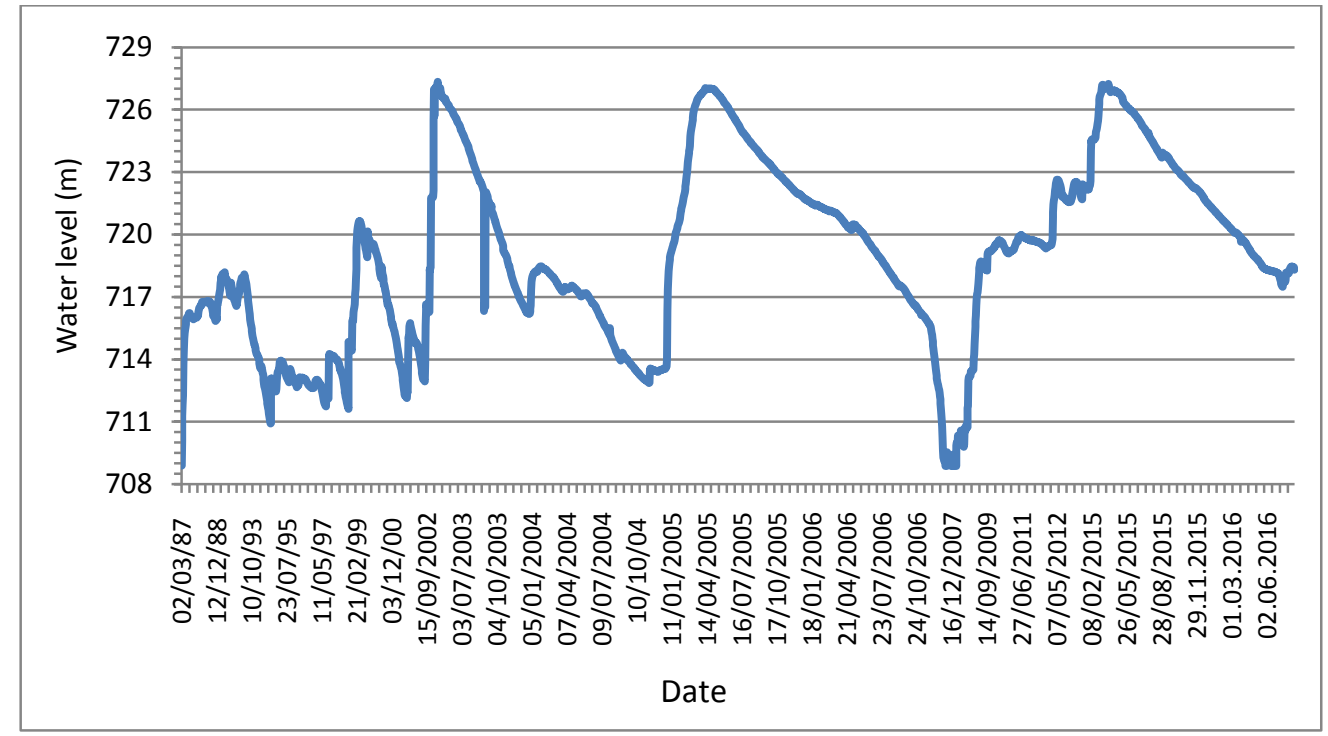

Figure 39. Variation in the water level at Hammam Grouz dam since its impoundment until the 2016/2017 hydrological year

The monitoring over time of the level of the water level in the lake shows that the latter, before the first waterproofing work and at each filling, will stabilize at levels below $714 \mathrm{~m}$ and after the last works it will be stabilizes at values that do not reach a level of $718 \mathrm{~m}$, which is equivalent to a water volume of less than $15 \mathrm{Hm}^{3}$, while the theoretical capacity is of the order of $45 \mathrm{Hm}^{3}$.

\section{Coefficient of Average Permeability at the Hammam Grouz Dam Lake}

The speed of descent of the water body is of great importance, which depends on several phenomena, namely: water releases (drinking water supply, flood evacuation and bottom drainage), losses (leaks, siltation and evaporation). The knowledge of all these parameters, allows to calculate the average speed of infiltration for a duration and a welldefined water level.

\section{Coefficient of Average Permeability at the Beginning of the Phenomenon}

The follow-up of the average permeability coefficient at the beginning of the appearance of the phenomenon of water leaks made it possible to draw Figure 40. Indeed, the average infiltration rate calculated is of the order of 2.069 $\mathrm{cm} /$ day for dimensions not exceeding $715 \mathrm{~m}$.

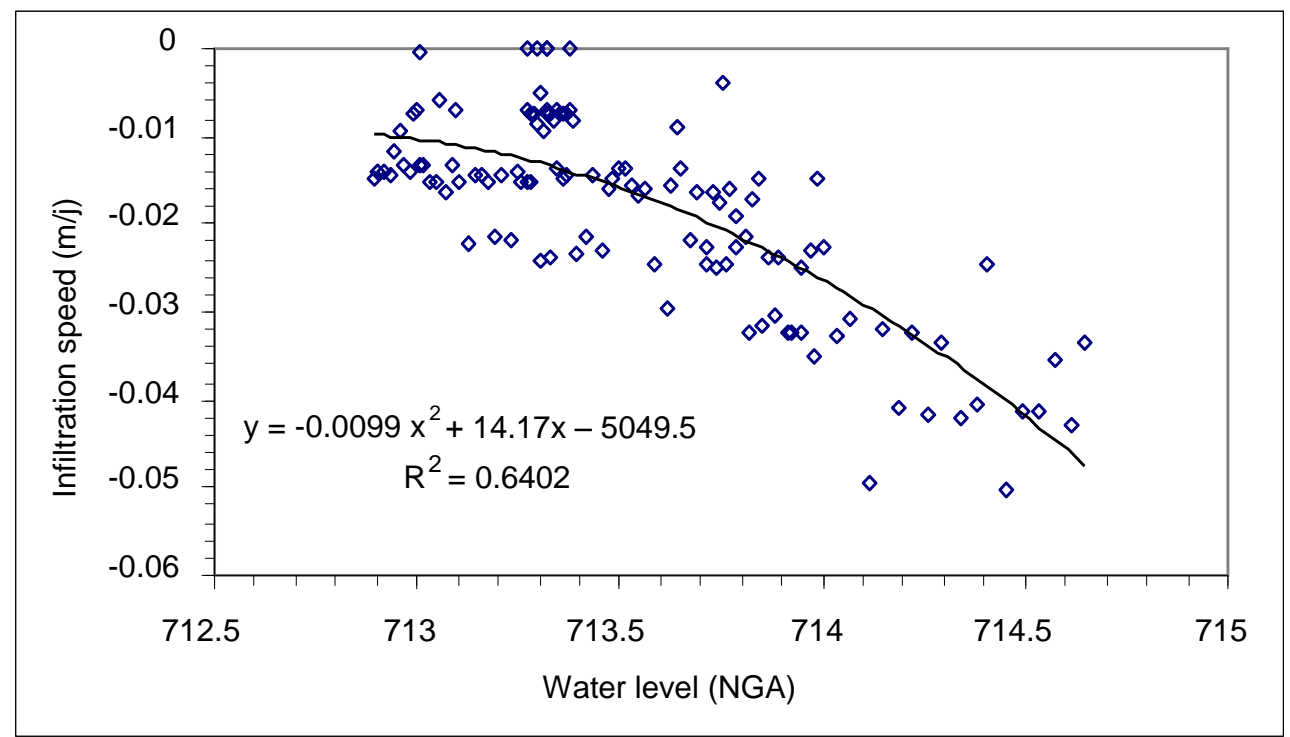

Figure 40. Variation of the infiltration speed depending on the water level of the lake at Hammam-Grouz dam, Algeria

Figure 40 illustrates the variation of the infiltration rate as a function of a dimension interval. It emerges that the explained variance does not follow a linear form, which indicates that it will be important for levels close to the spillway. 


\section{Current Average Permeability Coefficient}

After having followed the average permeability coefficient at the onset of the phenomenon, we decided to follow it after the last waterproofing work to visualize the fluctuation of this parameter. Figure 41 illustrates the fluctuation of this coefficient as a function of the level of the water body.

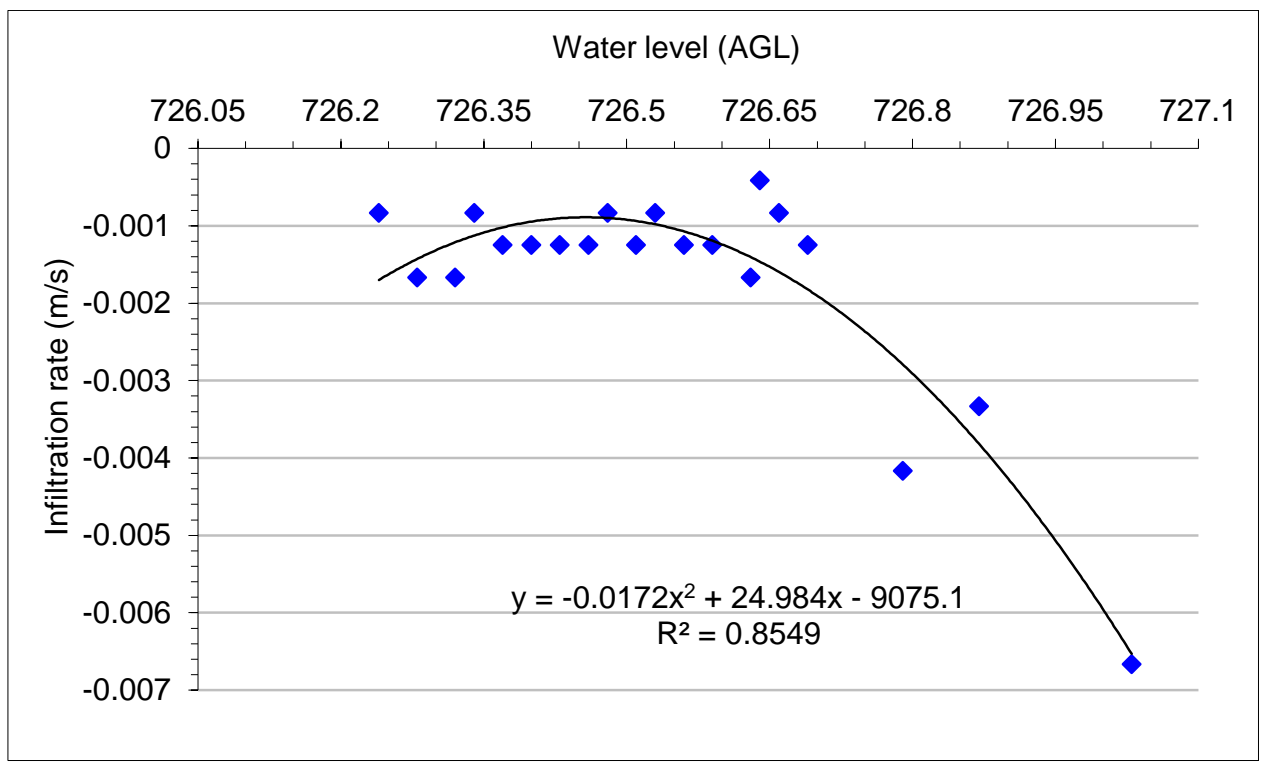

Figure 41. Variation of the infiltration speed depending on the water level of the lake at Hammam-Grouz dam, Algeria

This representation indicates that the rate of infiltration increases with the rise of water in the lake.

\section{Conclusions}

A dam is a hydraulic structure built to store water, protect against floods, produce electricity, provide recreation, fish farming, etc. But the construction of a dam on a site is unfavorable to storage and favorable to leaks. Through the system of supports, foundation and basin, water can cause problems ranging from loss of precious and rare water, especially in arid and semi-arid areas, to threats that may compromise the stability of the dike. In fact, any dam around the world knows during its first filling some problems related to tightness, which would require additional consolidation work to minimize or remove altogether. But the case of Hammam-Grouz dam is among the cases where water leaks through its foundation and especially its right bank, has far exceeded the reasonable threshold. The quantity of water lost can exceed $1.5 \mathrm{~m}^{3} / \mathrm{s}$ at the level of the normal level of the reservoir and the phenomenon has become repetitive at each arrival of a large flood, that is to say, at each climb from the water level to the turns of the normal level of the reservoir. The waterproofing services carried out to date have given satisfactory results, but they remain far from the ambitions of the services concerned. Indeed, the closure of the $1^{\text {st }}$ vortex, the veil of injection, carried out on the flank must, and the filling of the second vortex did not solve the definitive problem. The waters would persist to escape from the lake of the dam at fluctuating flows, to the course of time, with the variation of the water body. Indeed, the actual storage capacity (stability of the water level for a long time) does not exceed 15 million cubic meters. Faced with this situation, the restoration of the water tightness of this structure by all possible means and techniques is necessary or even mandatory in order to have a stable dike and a system composed of the lake. The foundation and the impervious shorelines will elevate the actual storage capacity to a higher value than the present one and will lead to reasonable operation of the dam and its surrounding and downstream environment.

Despite the fact that the dam, in this situation, plays other beneficial roles such as flood protection of all properties and populations along Rhumel river on the one hand and it protects the Beni Haroun dam against siltation on the other hand (it is located upstream of Beni Haroun dam). It presents risks to thermal springs located downstream (if no intervention is taken in the immediate future, these hot springs can have a major problem which may lead to their disappearance, we have seen the mixing of hot springs with cold water coming from the dam). In addition, it has hampered the exploitation of downstream boreholes (it has put under pressure downstream water tables) and it has generated threats to the stability of the dike because the lower tunnel would be emerged by interrupting the monitoring and control of the measures much more related to the stability of the dike.

A more detailed study of the geology of the dam site and its connection with the problems encountered before, during, and after the construction of the dam is even essential to better understand the problem of leaks at Hammam Grouz dam. The situation at the Hammam-Grouz dam is worrying because of the gradual deterioration of the clay carpet and the right bank by the underground flow, which leads to an increase in the flow of water leaks over time. As a result, this phenomenon creates major risks to the stability of the structure. 
Therefore, the search for a quick and effective solution is necessary as soon as the phenomenon appears. Reinforcement of the injection curtain more particularly at the level of the right bank, is an option not to be excluded. Moreover, to save such a structure against this phenomenon is a sine qua non and obligatory condition to ensure its stability or to guarantee its water tightness in order to use it as a second work of the future in case of a problem at the mega pumping station from Beni Haroun dam.

\section{Declarations}

\subsection{Author Contributions}

A.T., and B.R. contributed to the design and implementation of the research, to the analysis of the results and to the writing of the manuscript. All authors have read and agreed to the published version of the manuscript.

\subsection{Data Availability Statement}

The data presented in this study are available on request from the corresponding author. The data are not publicly available due to "providing by the national dams agency and transfers to perform this research in order to solve geological problems at dams".

\subsection{Funding}

The authors received no financial support for the research, authorship, and/or publication of this article.

\subsection{Acknowledgements}

Our thanks to the entire team of the national dams and transfers agency, in particular the Hammam Grouz dam operating team.

\subsection{Institutional Review Board Statement}

Not applicable.

\subsection{Informed Consent Statement}

Not applicable.

\subsection{Declaration of Competing Interest}

The authors declare that there is no conflict of interests regarding the publication of this manuscript. In addition, the ethical issues, including plagiarism, informed consent, misconduct, data fabrication and/or falsification, double publication and/or submission, and redundancies have been completely observed by the authors.

\section{References}

[1] Toumi, A., \& B. Remini, (2003). Leakage through the banks of the Foum el Gherza dam, Biskra, Algeria”. Magazine of Québec Science and Environmental Technology, 3(6), 67-71.

[2] Benfetta, H., and Remini, B. (2008). "Water leaks through the Ouizert algerian dam" Dry Magazine (France), 19 (3), 185-192.

[3] Toumi, A., (2009). Study of water leaks in dams; some examples from eastern Algeria, PhD thesis es sciences in Hydraulics and water sciences, 258 pages. Mohamed Kheider University, Biskra, Algeria.

[4] Abdelouaheb, T., \& Boualem, R. (2018). The problem of water leakage in beni haroun reservoir (Algeria). Jordan Journal of Civil Engineering, 12(3), 402-423.

[5] Toumi, A., \& B. Remini, (2008). Water leakages through banks of Hammam-Grouz dam (Algeria). European Journal of Scientific Research, 24(4), 491-497.

[6] Durozoy G., (1960). Study of the chateaudun region of Rhumel river, pub. serv. Geol. card Algeria NIIe series n²2, Algiers.

[7] Toumi, A., \& B. Remini, (2005). The problem of water leaks from Hammam Grouz dam. Larhyss Journal, 05, 41-48.

[8] N.A.D.T, (2004), Stability Control by high pressure topometric measurements and auscultation devices of the Hammam Grouz dam, maintenance and control department, Ministry of Water Resources, Algeria.

[9] National Agency for Dams and Transfers (N.A.D.T). (2004). Service operating of Grouz Hammam Dam (HG.D), Algeria.

[10] Binnie (1980), Hammam Grouz dam, Monograph, 49 Pages, Algeria.

[11] N.A.D.T, (2003), Report of the visit to the Hammam-Grouz dam, maintenance and control department, Ministry of Water Resources, Algeria. 
[12] N.A.D.T, (2008), Report of the visit to the site of Hammam Grouz dam. Company GeoMag and Dar Al-Handassa, Algeria.

[13] Mozafari, M., Milanović, P., \& Jamei, J. (2021). Water leakage problems at the Tangab Dam Reservoir (SW Iran), case study of the complexities of dams on karst. Bulletin of Engineering Geology and the Environment, 80(10), $7989-8007$. doi:10.1007/s10064-021-02387-z.

[14] Liu, S., Wang, X., Fu, L., \& Wei, B. (2018). Application of borehole radar for dam leakage detection. 2018 17th International Conference on Ground Penetrating Radar (GPR). doi:10.1109/icgpr.2018.8441615.

[15] Liu, B., Wang, C., Liu, Z., Xu, Z., Nie, L., Pang, Y., ... Feng, S. (2021). Cascade surface and borehole geophysical investigation for water leakage: A case study of the Dehou reservoir, China. Engineering Geology, 294, 106364. doi:10.1016/j.enggeo.2021.106364.

[16] N.A.D.T, (2003), Technical Report on Leaks, Maintenance and Control Department, Ministry of Water Resources, Algeria.

[17] Hocini. N, (2003), Investigation of leaks at the Hammam Grouz dam (Athmenia river), Algiers nuclear research Center (A.N.R.C), Nuclear applications division, Department of Applications in Hydrology and Sedimentology, Algeria. 